US Army Corps of Engineers $s_{\circledast}$

Engineer Research and

Development Center

\title{
A Multi-biome Study of Tree Cover Detection Using the Forest Cover Index
}

Sarah J. Becker, Megan C. Maloney, and Andrew W. H. Griffin

September 2021 
The U.S. Army Engineer Research and Development Center (ERDC) solves the nation's toughest engineering and environmental challenges. ERDC develops innovative solutions in civil and military engineering, geospatial sciences, water resources, and environmental sciences for the Army, the Department of Defense, civilian agencies, and our nation's public good. Find out more at www.erdc.usace.army.mil.

To search for other technical reports published by ERDC, visit the ERDC online library at https://erdclibrary.on.worldcat.org/discovery. 


\section{A Multi-biome Study of Tree Cover Detection Using the Forest Cover Index}

Sarah J. Becker, Megan C. Maloney, and Andrew W. H. Griffin

Geospatial Research Laboratory

U.S. Army Engineer Research and Development Center

7701 Telegraph Road

Alexandria, VA 22315

Final report

Approved for public release; distribution is unlimited.

Prepared for Engineer Research and Development Center

Alexandria, VA 22315

Under Project Element Number PE 633463, “Enhanced Terrain Processing”

Project Number AU1 


\section{Abstract}

Tree cover maps derived from satellite and aerial imagery directly support civil and military operations. However, distinguishing tree cover from other vegetative land covers is an analytical challenge. While the commonly used Normalized Difference Vegetation Index (NDVI) can identify vegetative cover, it does not consistently distinguish between tree and low-stature vegetation. The Forest Cover Index (FCI) algorithm was developed to take the multiplicative product of the red and near infrared bands and apply a threshold to separate tree cover from non-tree cover in multispectral imagery (MSI). Previous testing focused on one study site using 2-m resolution commercial MSI from WorldView-2 and 30-m resolution imagery from Landsat-7. New testing in this work used 3-m imagery from PlanetScope and 10-m imagery from Sentinel-2 in imagery in sites across 12 biomes in South and Central America and North Korea. Overall accuracy ranged between $23 \%$ and $97 \%$ for Sentinel-2 imagery and between $51 \%$ and $98 \%$ for PlanetScope imagery. Future research will focus on automating the identification of the threshold that separates tree from other land covers, exploring use of the output for machine learning applications, and incorporating ancillary data such as digital surface models and existing tree cover maps.

DISCLAIMER: The contents of this report are not to be used for advertising, publication, or promotional purposes. Citation of trade names does not constitute an official endorsement or approval of the use of such commercial products. All product names and trademarks cited are the property of their respective owners. The findings of this report are not to be construed as an official Department of the Army position unless so designated by other authorized documents. 


\section{Contents}

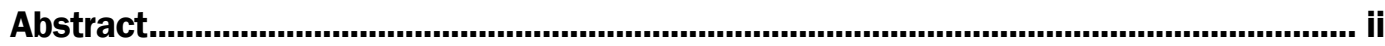

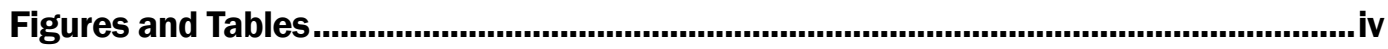

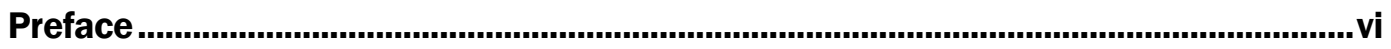

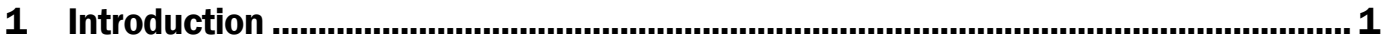

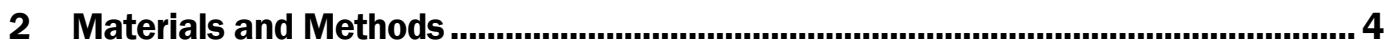

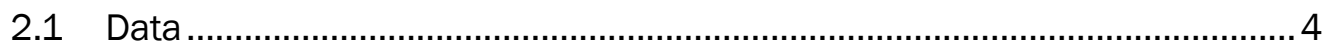

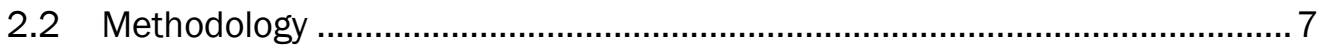

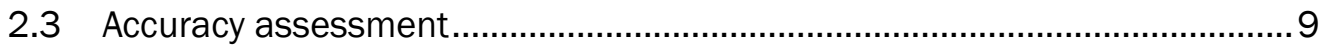

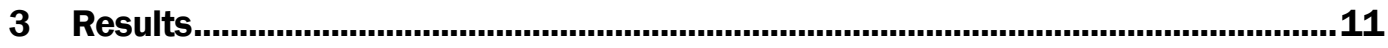

3.1 NDVI pre-mask and Forest Cover Index result and error ............................11

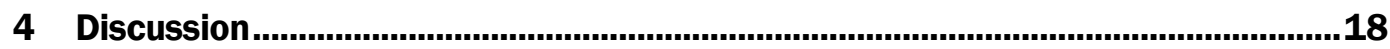

4.1 Limitations and recommendations for improvement ................................. 19

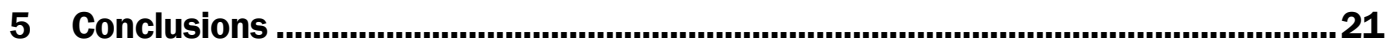

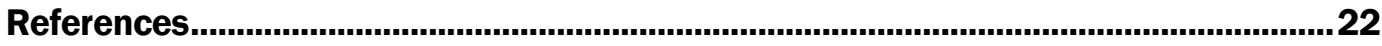

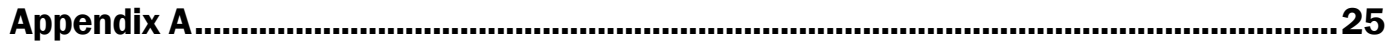

Report Documentation Page 


\section{Figures and Tables}

\section{Figures}

Figure 1. A comparison of FCl to NDVI using WorldView-2 multispectral imagery at the U.S. Department of Agriculture's Beltsville Agricultural Research Center in Beltsville, MD: (a) the original image from August 5, 2012; (b) FCl output; and (c) NDVI output. Adjusting the user-defined threshold in NDVI caused a trade-off between capturing cleared paths on the left side of the image and excluding the agricultural field in the bottom center. The $\mathrm{FCl}$ was better able to exclude the low stature vegetation in the agricultural field and gaps in the canopy on the center right as well as the paths on the left.

Figure 2. Sites selected for multi biome testing of $\mathrm{FCl}$.

Figure 3. The Kappa values for each biome for PlanetScope and Sentinel-2. Kappa values at 0.70 and greater were determined to be accurate classifications of tree cover in the imagery.

Figure 4. The overall accuracies for each biome for PlanetScope and Sentinel-2.

Figure 5. Result of a PlanetScope image from the "tropical and subtropical moist broadleaf forest" biome showing: (a) a subset of the original image; (b) a grayscale raster showing $\mathrm{FCl}$ output; (c) the classified raster after the NDVI mask and $\mathrm{FCl}$ mask are applied, showing tree cover in black and non-tree cover in red; and (d) in the PlanetScope imagery only, the classified raster after sieve and clump smoothing algorithms are applied.

Figure 6 . The $\mathrm{FCl}$ performed most accurately in images with dense tree canopy, such as during leaf-on seasons in tropical biomes. For example, in the "tropical and subtropical grasslands, savannas, and shrublands" and "tropical and subtropical dry broadleaf forest" biomes depicted above, both sensors achieve high accuracy.

Figure 7. The $\mathrm{FCl}$ performed poorly in distinguishing trees from other land covers when trees were senescent, or wetlands were present. Sentinel-2 (a and c) and PlanetScope ( $b$ and d) imagery show poor accuracy when senescent trees were present adjacent to a marshy reservoir ( $a$ and $c$ ) or tree cover grew alongside marshland ( $b$ and d).

\section{Tables}

Table 1. PlanetScope multispectral $3 \mathrm{~m}$ resolution bands (Planet Team 2017).

Table 2. Sentinel-2 multispectral $10 \mathrm{~m}$ resolution bands (European Space Agency 2020)

Table 3. The listed biomes were selected for $\mathrm{FCl}$ testing due to availability of overlapping imagery containing the land cover of interest in cloud-free seasonal intervals from Sentinel-2 and PlanetScope sensors. The Ecoregions 2017 dataset was used to stratify random sampling to biome level. Two biomes were excluded: "boreal forests / taiga" and "temperate conifer forests" due to lack of spatial coverage by PlanetScope and the "tundra" biome due to lack of the target tree cover. 
Table 4. The range of user selected $\mathrm{FCl}$ thresholds used in each biome for each sensor.

Table A1. Producer's, user's, and overall accuracy for Tree versus Not Tree classifications for the $\mathrm{FCl}$ in PlanetScope and Sentinel-2 imagery for each date and biome.

Table A2. The individual error matrix of Kappa analysis results. A Z-statistic greater than 1.96 indicates the classification is better than random. 


\section{Preface}

This study was conducted for the Geospatial Research Laboratory under Program Element Number PE 633463, "Enhanced Terrain Processing," Project Number AU1.

The work was performed by the Data Signature and Analysis Branch (TRS) of the TIG Research Division (TR), U.S. Army Engineer Research and Development Center, Geospatial Research Laboratory (ERDC-GRL). At the time of publication, Ms. Jennifer Smith was Chief, Data Signature and Analysis Branch; Mr. Jeffrey Murphy was Chief, TIG Research Division (CEERD-TR); and Mr. Ritchie Rodebaugh was the Technical Director of the Technical Directorate (CEERD-TET). The Deputy Director of ERDCGRL was Ms. Valerie Carney and the Director was Mr. Gary Blohm.

The authors would like to thank the following Engineer Research and Development Center staff: Nicole Wayant and Jean Nelson for their leadership at USACE; Nicole Wayant additionally for her help during the conception, execution, and review of the project; Susan Lyon for her review of this project; and Sean Griffin for creating a tool to automate the FCI algorithm and his review of the project.

The Commander of ERDC was COL Teresa A. Schlosser and the Director was Dr. David W. Pittman. 


\section{Introduction}

Scientists at the U.S. Army Corps of Engineers' (USACE) Engineer Research and Development Center developed an algorithm to expedite tree identification in multispectral imagery (MSI). Tree cover impacts military operations by impeding vehicle and troop movement, preventing helicopter access, and providing concealment. Tree cover mapping also supports civil applications such as wildfire modeling and forest inventory. While the Normalized Difference Vegetation Index (NDVI) is often used to study vegetation, prior research developed the Forest Cover Index (FCI) using the red and near infrared (NIR) bands from multispectral sensors to further distinguish tree cover within mixed vegetation (Becker et al. 2018; Feliciano-Cruz et al. 2019). The FCI was previously tested at the U.S. Department of Agriculture's Beltsville Agricultural Research Center in Beltsville, MD on urban land cover, closed canopy forest cover, and dense agriculture (Becker et al. 2018). This research expands upon that project by testing imagery containing tree cover from different satellite sources in multiple biomes to evaluate whether the FCI index is globally applicable.

To identify tree cover, the FCI considers pixels independently, and the resolution of input imagery determines the output. For coarse resolutions, the FCI output may fit the definition of forest cover, meaning pixels describe relatively large contiguous groups of trees. However, as highresolution inputs become more commonly available, the output is best defined as tree cover rather than forest cover because the small pixel sizes allow identification of small groups or individual trees. As this study uses high-resolution imagery, output will be referred to as tree cover throughout.

Prior research methods on tree cover identification have limitations that we seek to address in this work. For example, popular indices such as NDVI detect vegetation generally rather than tree cover specifically (Chen 1996; Rouse 1973). Other tree cover detection methods may rely on data that are costly to acquire, limited in coverage, or difficult to manage or interpret such as hyperspectral imagery (HSI), synthetic aperture radar (SAR), or light detection and ranging (LiDAR) data (Chen et al. 2006; Heckel et al. 2020; Ke and Quackenbush 2011; Graves et al. 2016; Wu et al. 2017). Machine learning approaches apply supervised and 
unsupervised classifications to MSI, which may be complex to apply, have high computation requirements, or depend on time-consuming collection of training data (Loveland et al. 2000; Kumar and Sinha 2020; Zhu and Evans 1994; Akar et al. 2017). Some studies focus on a single biome or forest type, or a limited study area (Akar et al. 2017; Ye et al. 2014; Chen 1996; Graves et al. 2016; Wu et al. 2017). Studies seldom sample across seasons to observe changes in performance under different conditions, such as leaf senescence or snow cover interference. To address these limitations, in this work we seek to apply an index method that is easy to interpret, uses commonly available MSI, and expands on previous work. Sites are tested across seasons and on tree cover in different biomes.

Healthy vegetation absorbs visible red wavelengths for photosynthesis while reflecting NIR wavelengths (Rouse 1973; Tucker 1979). The FCI investigated in this report builds on the unique "red edge" response of vegetation to the combination of red and NIR ranges of reflectance (Richardson and Wiegand 1977). This response has been leveraged in many other indices. For example, NDVI is the most used index, which normalizes the difference between NIR and red bands and is often used to study vegetative vigor. Variations on NDVI such as the Enhanced Vegetation Index and the Soil Adjusted Index adjust the NDVI formula to reduce background interference, though this may reduce sensitivity to overstory conditions (Chen 1996; Tucker 1979; Jiang et al. 2008). The FCI builds off previous studies by using a multiplicative product of red and NIR to exaggerate the response to distinguish tree cover from other vegetative cover.

Becker et al. (2018) explored the reflectance of vegetation and found that tree canopy consistently showed lower reflectance in the red and NIR wavelengths compared to other vegetation types at the Beltsville Agricultural Research Center. Based on this difference in reflectance, the FCI was created to be a simple binary algorithm that could quickly separate tree cover from non-tree cover in imagery without using training data. Prior research employed binary thresholding to delineate trees using grayscale or multispectral imagery or in combination with more labor intensive approaches or using HSI but achieved mixed results (Pitkanen 2001; Bunting 2006), which prompted Becker et al. (2018) to develop the FCI (Pouliot et al. 2002). The FCI was then applied to 2-m WorldView-2 multispectral imagery over the Beltsville Agricultural Research Center using four quarterly dates to capture seasonal variation (Becker et al. 
2018). The FCI output was validated using selective non-random sampling, producing an overall accuracy between 77-99\% across seasons with a Kappa of 57-99\% (Becker et al. 2018). Becker et al. (2018) also included NDVI testing in their tree cover mapping and found that FCI outperformed NDVI in mapping tree cover (Figure 1). NDVI performed poorly in distinguishing tree cover from low statures vegetation in summer, fall, and winter. The spring accuracy statistics for NDVI were high, but upon visual examination of the imagery, they found foliage had returned to trees but many agricultural fields were unplanted or contained immature crops, indicating that the NDVI was merely identifying tree cover because it was the only visible vegetation at the time. Feliciano-Cruz et al. (2019) tested on a 30-m Landsat-7 image of the same location, using a random stratified sampling validation, and produced a similar overall accuracy of $84-96 \%$ across seasons with a similar Kappa of $68 \%-91 \%$. The following work applies these methods to a larger dataset, collected from two additional sensors, to determine if FCI performance operates robustly in different environments and seasonal conditions.

Figure 1. A comparison of FCl to NDVI using WorldView-2 multispectral imagery at the U.S. Department of Agriculture's Beltsville Agricultural Research Center in Beltsville, MD: (a) the original image from August 5, 2012; (b) FCl output; and (c) NDVI output. The output in green denotes tree cover and red denotes all other land covers. Adjusting the user-defined threshold in NDVI caused a trade-off between capturing cleared paths on the left side of the image and excluding the agricultural field in the bottom center. The $\mathrm{FCl}$ was better able to exclude the low stature vegetation in the agricultural field and gaps in the canopy on the center right as well as the paths on the left.

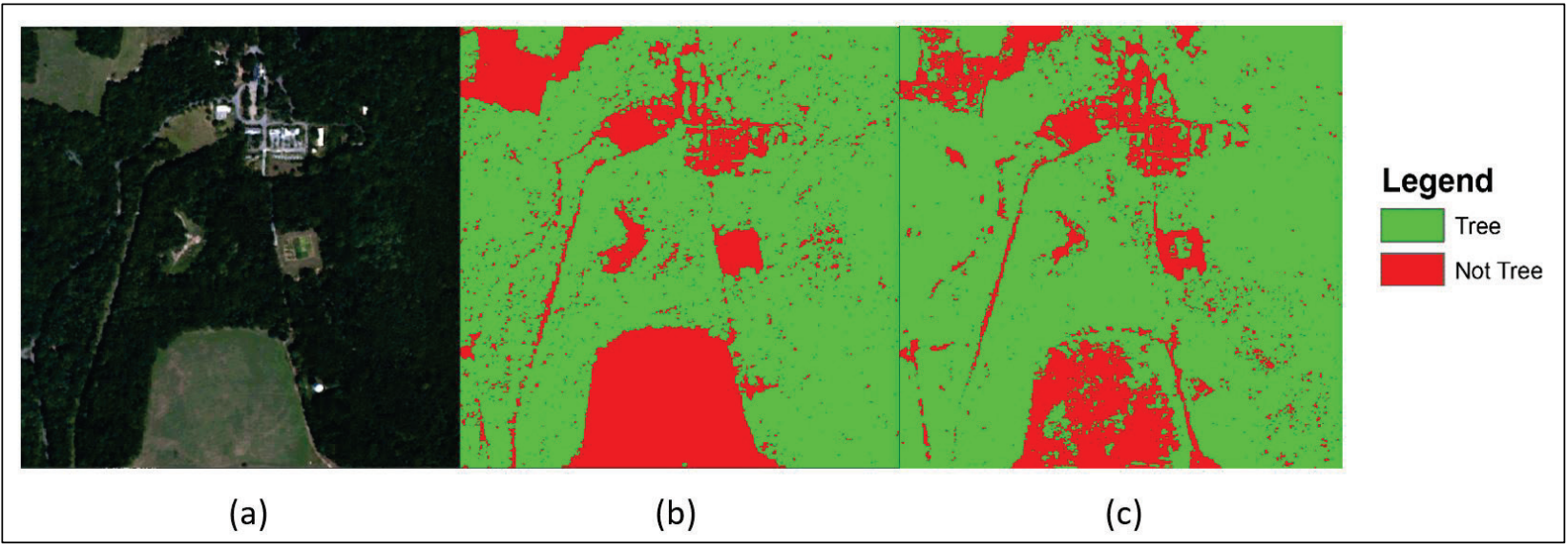




\section{Materials and Methods}

\subsection{Data}

PlanetScope and Sentinel-2 MSI were selected for this study due to their high repeat returns and historical archives, which better support seasonal collection of cloud free imagery (Planet Team 2017; European Space Agency 2020). The PlanetScope satellite is a 4-band multispectral sensor that measures reflectance in the visible and NIR regions of the electromagnetic spectrum from 455 to $860 \mathrm{~nm}$ with a spatial resolution of approximately $3 \mathrm{~m}$ at nadir (Table 1 ). Sentinel-2 is a 12-band multispectral sensor that measures between 443 to $2,190 \mathrm{~nm}$ with three visible and one NIR band at a spatial resolution of approximately $10 \mathrm{~m}$ at nadir for the visible and NIR bands (Table 2).

Table 1. PlanetScope multispectral $3 \mathrm{~m}$ resolution bands (Planet Team 2017).

\begin{tabular}{|l|l|l|l|}
\hline Band Name & Band \# & Band Center $(\mathrm{nm})$ & Band Range $(\mathrm{nm})$ \\
\hline Blue & 1 & 485 & $455-515$ \\
\hline Green & 2 & 545 & $500-590$ \\
\hline Red & 3 & 630 & $590-670$ \\
\hline Near infrared & 4 & 820 & $780-860$ \\
\hline
\end{tabular}

Table 2. Sentinel-2 multispectral $10 \mathrm{~m}$ resolution bands (European Space Agency 2020).

\begin{tabular}{|l|l|l|l|}
\hline Band Name & Band \# & Band Center $(\mathrm{nm})$ & Band Range $(\mathrm{nm})$ \\
\hline Blue & 2 & 490 & $458-523$ \\
\hline Green & 3 & 560 & $543-578$ \\
\hline Red & 4 & 665 & $650-680$ \\
\hline Near infrared & 8 & 842 & $785-899$ \\
\hline
\end{tabular}

Biomes were used to stratify random site selection to ensure that variation in common environmental conditions were represented in the sample. Biome boundaries were defined using geospatial data from the Ecoregions 2017 report (Dinerstein et al. 2017; Olson et al. 2001). Within each biome, 10 randomly placed 2 square mile sites were generated and reviewed. The first site that met the following criteria was chosen for each biome: 1) the site contained the target land cover (tree cover) and non-tree land covers for comparison (low stature vegetation such as grassland or pasture, infrastructure, water), and 2) the site had as close to quarterly as possible four cloud-free images available so that a seasonal comparison could be 
made. PlanetScope imagery was available to USACE for this project in most of South and Central America, and portions of East Asia; however, biomes such as the boreal forest/taiga and temperate conifer forests were excluded for lack of imagery. The 12 biomes selected are shown in Table 3 below and their locations are shown in Figure 2.

Table 3. The listed biomes were selected for $\mathrm{FCl}$ testing due to availability of overlapping imagery containing the land cover of interest in cloud-free seasonal intervals from Sentinel-2 and PlanetScope sensors. The Ecoregions 2017 dataset was used to stratify random sampling to biome level. Two biomes were excluded:

"boreal forests / taiga" and "temperate conifer forests" due to lack of spatial coverage by PlanetScope and the "tundra" biome due to lack of the target tree cover.

\begin{tabular}{|c|c|c|}
\hline Site \# & Biome & Coordinates \\
\hline 01 & $\begin{array}{l}\text { Tropical and subtropical } \\
\text { moist broadleaf forest }\end{array}$ & $75^{\circ} 50^{\prime} 52.904^{\prime \prime W} 1^{\circ} 6^{\prime} 21.416 " \mathrm{~N}$ \\
\hline 02 & $\begin{array}{l}\text { Tropical and subtropical } \\
\text { dry broadleaf forest }\end{array}$ & $42^{\circ} 24^{\prime} 37.426^{\prime \prime W} 7^{\circ} 35^{\prime} 15.802^{\prime \prime S}$ \\
\hline 03 & $\begin{array}{l}\text { Tropical and subtropical } \\
\text { coniferous forest }\end{array}$ & $87^{\circ} 56^{\prime} 30.266^{\prime \prime W} 14^{\circ} 40^{\prime} 5.354^{\prime \prime} \mathrm{N}$ \\
\hline 04 & $\begin{array}{l}\text { Tropical and subtropical } \\
\text { grasslands, savannas and } \\
\text { shrublands }\end{array}$ & $59^{\circ} 22^{\prime} 11.449 " \mathrm{~W} 22^{\circ} 20^{\prime} 46.377^{\prime \prime S}$ \\
\hline 05 & $\begin{array}{l}\text { Temperate grasslands, } \\
\text { savannas and shrublands }\end{array}$ & $59^{\circ} 36^{\prime} 30.708^{\prime \prime W} 30^{\circ} 46^{\prime} 10.397^{\prime S}$ \\
\hline 06 & $\begin{array}{l}\text { Flooded grasslands and } \\
\text { savannas }\end{array}$ & $\begin{array}{l}56^{\circ} 55^{\prime} 43.603^{\prime \prime} \mathrm{W} \\
18^{\circ} 46^{\prime} 56.078^{\prime \prime S s}\end{array}$ \\
\hline 07 & $\begin{array}{l}\text { Montane grasslands and } \\
\text { shrublands }\end{array}$ & $64^{\circ} 58^{\prime} 17.131 " W 22^{\circ} 34^{\prime} 54.172^{\prime \prime S}$ \\
\hline 08 & Rock and ice & $73^{\circ} 35^{\prime} 13.702 " \mathrm{~W} 50^{\circ} 28^{\prime} 7.463^{\prime \prime S}$ \\
\hline 09 & $\begin{array}{l}\text { Mediterranean forests, } \\
\text { woodlands and scrub }\end{array}$ & 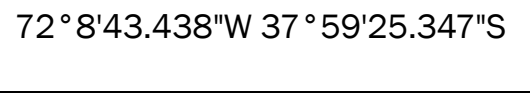 \\
\hline 10 & $\begin{array}{l}\text { Deserts and xeric } \\
\text { shrublands }\end{array}$ & $64^{\circ} 54^{\prime} 16.494^{\prime \prime W} 8^{\circ} 56^{\prime} 50.93^{\prime \prime N}$ \\
\hline 11 & Mangroves & $83^{\circ} 33^{\prime} 5.149 " \mathrm{~W} 12^{\circ} 55^{\prime} 40.034^{\prime \prime} \mathrm{N}$ \\
\hline 12 & $\begin{array}{l}\text { Temperate broadleaf and } \\
\text { mixed forest }\end{array}$ & $\begin{array}{l}125^{\circ} 31^{\prime} 42.547 " \mathrm{E} \\
37^{\circ} 59^{\prime} 15.081^{\prime \prime N}\end{array}$ \\
\hline
\end{tabular}


Figure 2. Sites selected for multi biome testing of $\mathrm{FCl}$ marked with black boxes. The biomes are differentiated by color

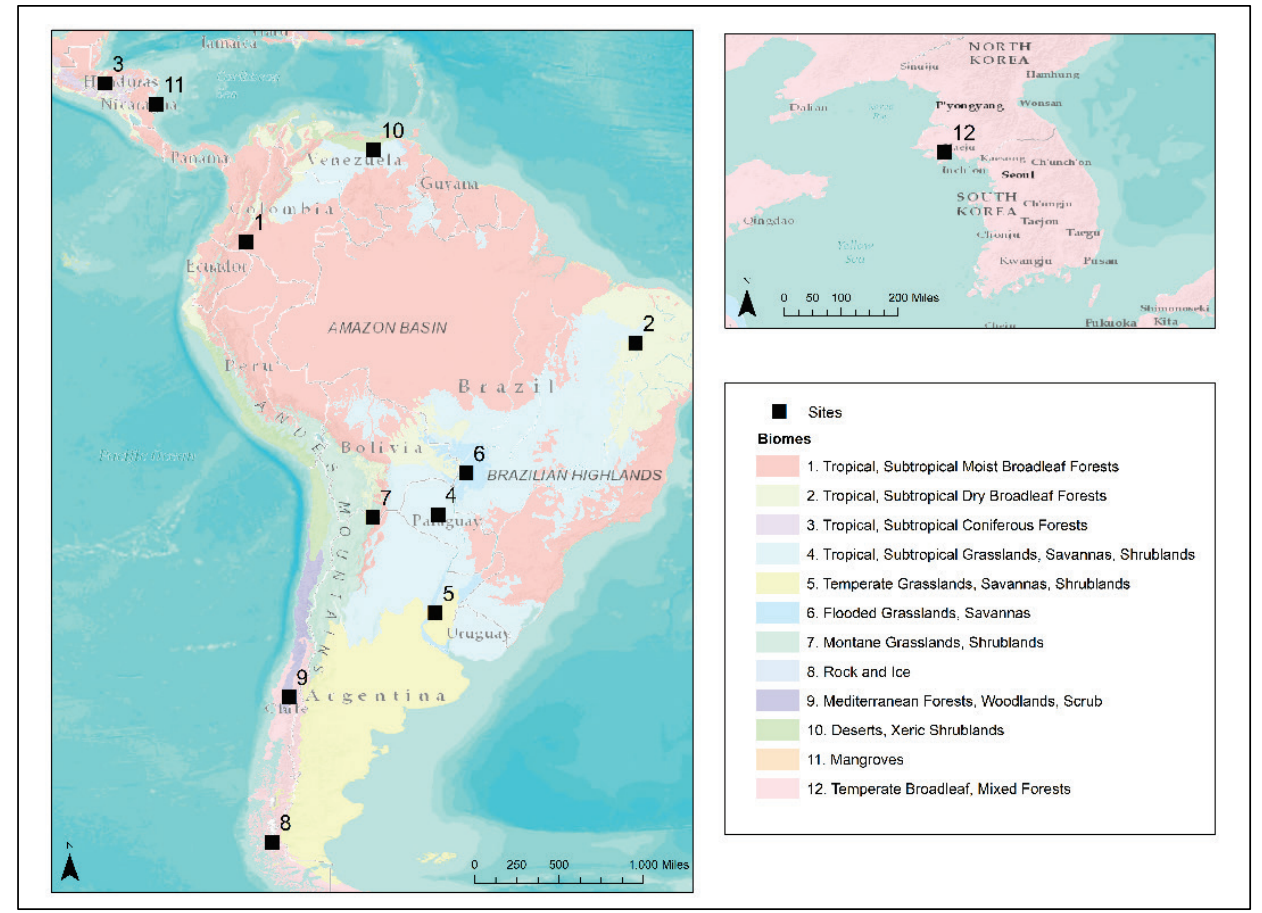

Stratified random sampling was used to select two-square mile sites in each of the 12 biomes. Researchers then visually inspected the selected sites using Google Earth and other supplementary open source imagery, with the goal of confirming sites contained both the target land cover, trees, and non-target land covers which the tool would need to differentiate. Following this approach, one site per biome was selected.

For each site, quarterly imagery was gathered to capture seasonal variation. If cloud-free imagery was not available for a quarter, imagery from the closest cloud-free date was substituted. A total of 48 PlanetScope images were collected spanning 2018 and 2019 and 47 Sentinel-2 images between 2017 and 2019. The PlanetScope images were radiometrically corrected to surface reflectance by Planet Labs, Inc. The PlanetScope images were processed using the commercial software, Environment for Visualizing Images (ENVI) (L3Harris Technologies, Melbourne, Florida). The Sentinel-2 images were collected with and without bottom-ofatmosphere (BOA) correction and, where necessary, were corrected to BOA using European Space Agency (ESA) Sen2Cor processor. Sentinel-2 imagery was downloaded from the ESA web portal, Copernicus Open Access Hub. 


\subsection{Methodology}

The FCI was developed to separate tree from non-tree land covers by multiplying the red by the NIR bands using the following equation for each satellite. The red and NIR bands are suitable to calculate tree cover because the spectral properties of canopy elements (including leaves and stems) are determined primarily by the concentrations of chlorophyll and other pigments in the visible ( 400 to $700 \mathrm{~nm}$ ) and leaf structure in the near infrared (700 to 1,200 $\mathrm{nm}$ ) wavelength regions (Clevers et al. 2010). The multiplicative product was chosen for this equation rather than a ratio because a ratio would normalize the difference between the red and NIR bands, whereas the multiplicative product exaggerates the difference between the two bands.

$$
\begin{array}{rr}
\mathrm{FCl}=\text { red * NIR } & \\
\mathrm{FCl}=\operatorname{red}(\text { Band 3) * NIR (Band 4) } & (\text { PlanetScope }) \\
\mathrm{FCl}=\text { red (Band 4) * NIR (Band 8) } & \text { (Sentinel -2) }
\end{array}
$$

The NDVI was used as a preliminary step to mask non-vegetation from the FCI input (Tucker 1979; Rouse 1973), because Becker et al. (2018) and Feliciano-Cruz et al. (2019) found confusion between tree cover and land covers that exhibited similar low FCI values, such as water, which led to the addition of the NDVI pre-mask in this research as a first step to eliminate land covers that yielded low FCI values. A default NDVI threshold of 0.4 was used to mask infrastructure, water, and other nonvegetative land covers. The default NDVI threshold value of 0.4 was chosen after comparing a selection of sites with NDVI thresholds ranging between $0.2-0.8$ to observe what land covers were removed. While a mask more individually tailored to local conditions may be preferable, little loss of tree cover was observed using 0.4 as a threshold in preliminary comparisons. NDVI is calculated using the following equation:

$$
N D V I=(N I R-\text { red }) /(\text { NIR }+ \text { red })
$$

The following workflow combining the NDVI pre-mask and FCI was applied to the imagery to separate trees from other land covers:

1. The NDVI equation was applied to the red and NIR bands of corrected PlanetScope and Sentinel-2 imagery. NDVI values below 0.4 were masked. 
2. The FCI equation was then applied to the red and NIR bands of the PlanetScope and Sentinel-2 pixels, which were not masked by NDVI at a 0.4 threshold. Determining the threshold for the FCI is user interactive; the user examined pixels of different land covers throughout the image and viewed the FCI values of different land covers. Tree pixels are generally darker than other pixels, giving tree pixels lower FCI values. The user determined a threshold for the FCI values to separate tree cover from other vegetative land covers. The user-selected FCI threshold was applied to further mask non-tree pixels.

3. Sieve and clump smoothing algorithms were applied to only PlanetScope FCI classified rasters to smooth speckling inside groups of tree pixels, which occurred in larger quantities in PlanetScope than Sentinel-2. Smoothing was not applied to Sentinel-2 FCI classified rasters because the coarser pixels risked reclassifying areas that were larger than the target gaps. Feliciano-Cruz et al. (2019) did not employ the postprocessing sieve and clump steps. Feliciano-Cruz et al. (2019) conducted their test with 30-m spatial resolution Landsat-7 and found that the pixel size of $30 \mathrm{~m}$ was too large to conduct post-processing sieve and clump steps as those steps erroneously removed forested areas. For PlanetScope imagery, which has spatial resolution of approximately $3 \mathrm{~m}$, testing showed that a group minimum of 200 pixels with 8 neighbors was selected as an appropriate sieve grouping to remove non-tree pixels from within groups of tree pixels. This smoothing operation only removes non-tree clusters from groups of pixels classified as trees; it does not remove tree pixels in non-tree areas. The 200-pixel cluster and 8-neighbor region settings were selected because they considered all 8 pixels surrounding an initial not tree pixel in groups of up to 200 pixels when considering whether a group of pixels was to be considered as not tree. A clump operation was then executed to fill in isolated areas of 3x3 pixels of non-tree pixels that were incorrectly identified as trees. The sieve and clump settings were selected because they yielded the optimal smoothing result. Mixed pixels were assigned to tree or non-tree based on the adjacent pixel in the upper left corner. This was done on the PlanetScope imagery to allow results to be comparable to previous work in which Becker et al. (2018) applied postprocessing smoothing steps to fine resolution 2-m WorldView-2 imagery. 
4. The combined NDVI and FCI masks, including the smoothing adjustment on PlanetScope classified rasters, were used to create a binary output classifying tree pixels separately from non-tree pixels.

\subsection{Accuracy assessment}

Error analysis used an equalized random sampling approach. One hundred random points per image were used for validation. Fifty points were randomly distributed in "tree" classified pixels and 50 points in "nontree" pixels using the binary output produced by the combined NDVI/FCI masks (Congalton 1991; Congalton and Green 2008). Researchers overlaid the 100 randomly sampled points on the NDVI/FCI output and the ground reference data, and then compared ground reference data to the binary classification at each randomly sampled point to determine if those 100 pixels had been correctly classified. Additionally, the areas surrounding the 100 randomly sampled pixels in the ground reference were analyzed to determine the context of sampled pixel. Imagery from Bing Maps Aerial, DigitalGlobe, ESRI World Imagery, and Google Earth were used as ground reference. Ground reference data of the exact same dates as the original images were not available, but multiple sources of ground reference were compared, some of which contained imagery at multiple dates and because tree cover can remain static, the ground reference was determined to be adequate to use in this research. If the equalized random sample generated a pixel on a cloud, the pixel was designated as a cloud and excluded from the error analysis.

Accuracy was calculated using the 100 validation pixels for each image using user's, producer's, and overall accuracies, after which the Kappa statistic was applied. The user's accuracy measures the error of commission where a land cover is committed or assigned to an incorrect category. The producer's accuracy measures errors of omission where pixels were omitted from the correct category. Overall accuracy is the number of correct classifications divided by the total number of samples (Story and Congalton 1986). The Kappa statistic compares actual to chance agreement between the computer classification of land cover and reference data (Congalton et al. 1983). The Kappa statistic, its variance, and the Z-statistic for a single error matrix were calculated to determine if the agreement between the classification and reference data were significantly better than random. At a 95\% confidence level, the critical value of the Z-statistic is 1.96, therefore any Z-statistic result above 1.96 indicates the classification is better than random (Congalton and Green 
2008). Error matrices with a Kappa greater than 0.70 and overall accuracies greater than 0.85 were determined to be accurate classifications of tree cover in the imagery. 


\section{Results}

\subsection{NDVI pre-mask and Forest Cover Index result and error}

Overall accuracy varied across seasons and biomes, ranging from $51 \%$ to 98\% in PlanetScope and from 23\% to 97\% in Sentinel-2 (Figures 3 and 4). User defined FCI thresholds varied as well (Table 4). A Kappa statistic of 0.70 was considered sufficient for this study, which roughly corresponds to an overall accuracy of $85 \%$. These cutoffs are indicated in Figures 3 and 4. The FCI performance was higher in many leaf-on scenes; however, a seasonal trend did not emerge across the biomes. 
Figure 3. The Kappa values for each biome for PlanetScope and Sentinel-2. Kappa values at 0.70 and greater were determined to be accurate classifications of tree cover in the imagery.

Kappa values across biomes

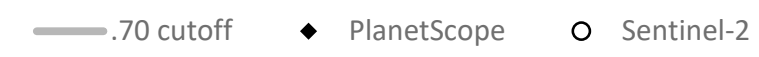

1.00

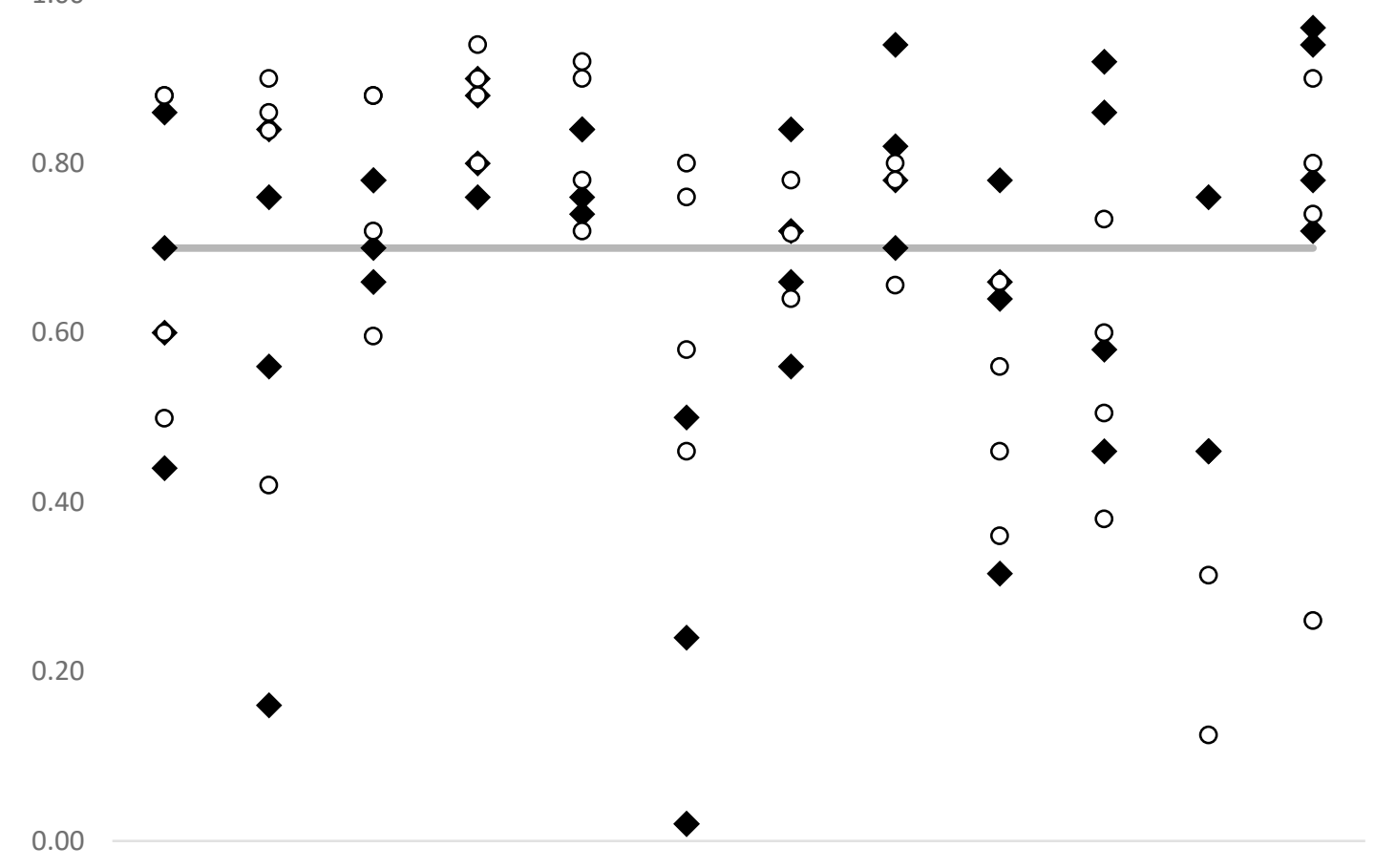

○

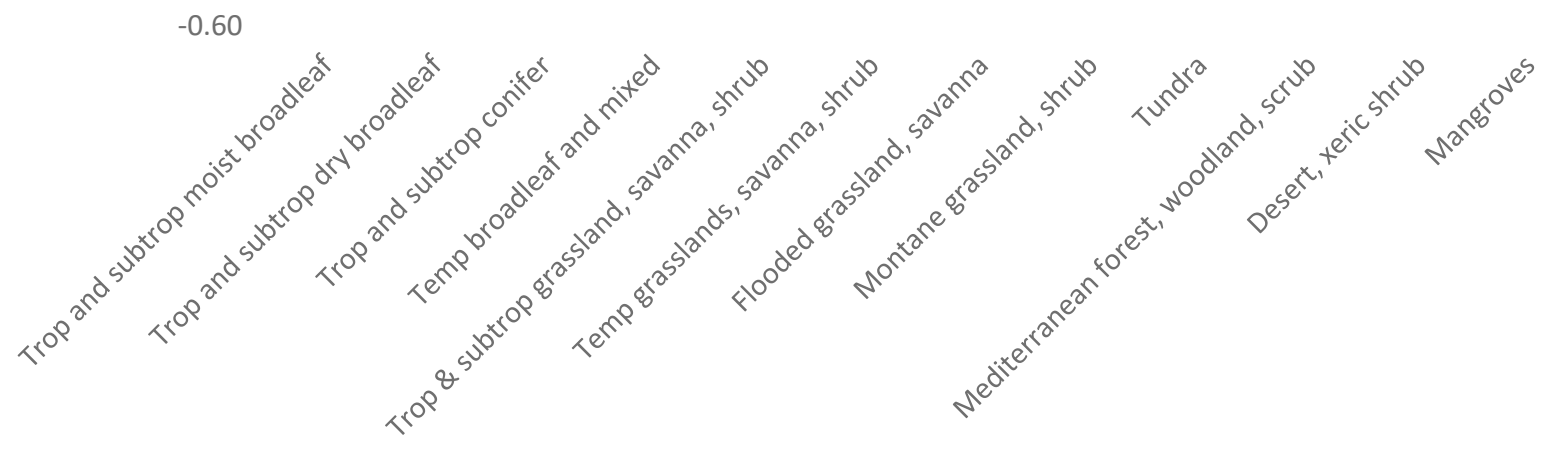


Figure 4. The overall accuracies for each biome for PlanetScope and Sentinel-2.

\section{Overall accuracy values across biomes}

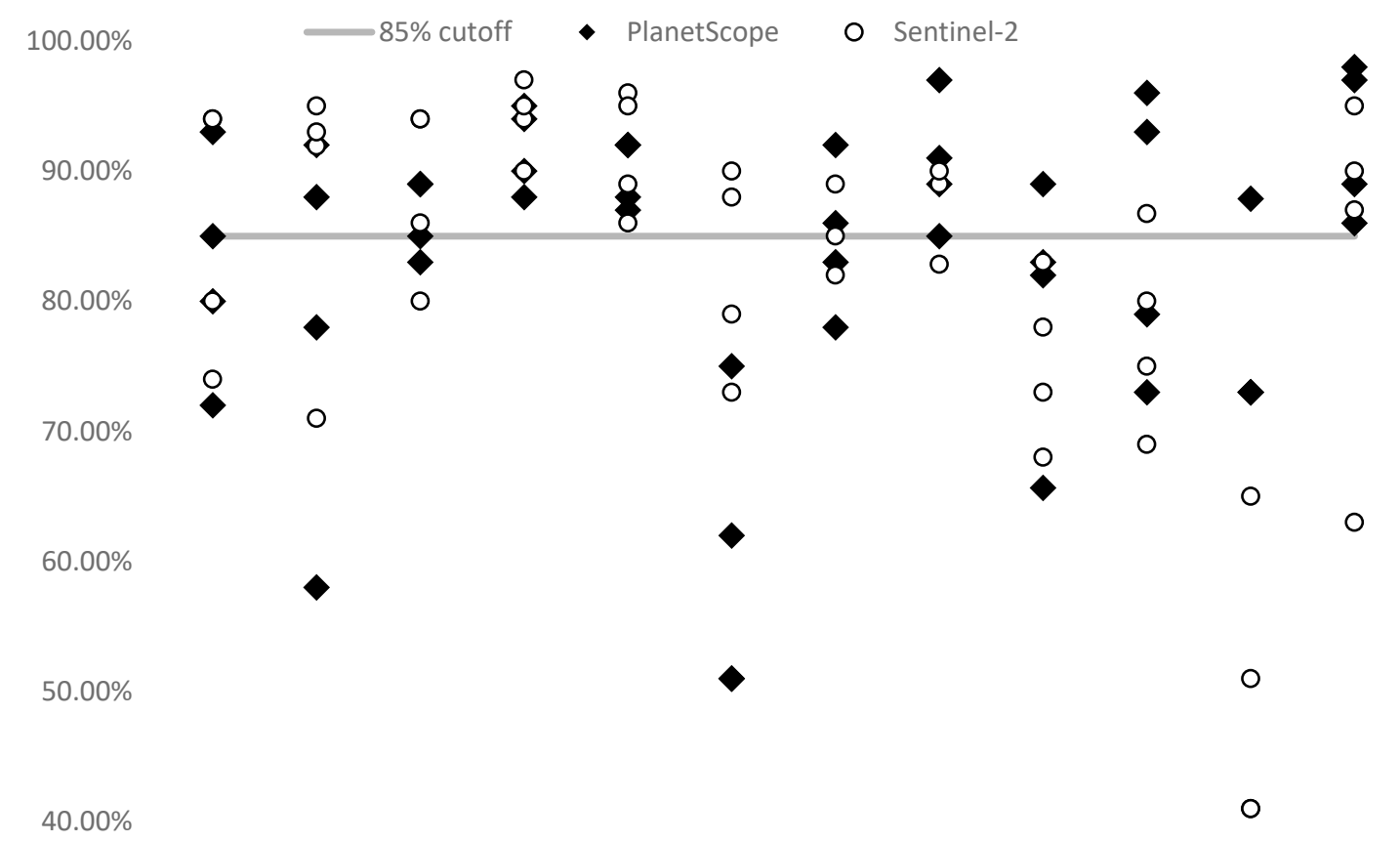

$30.00 \%$

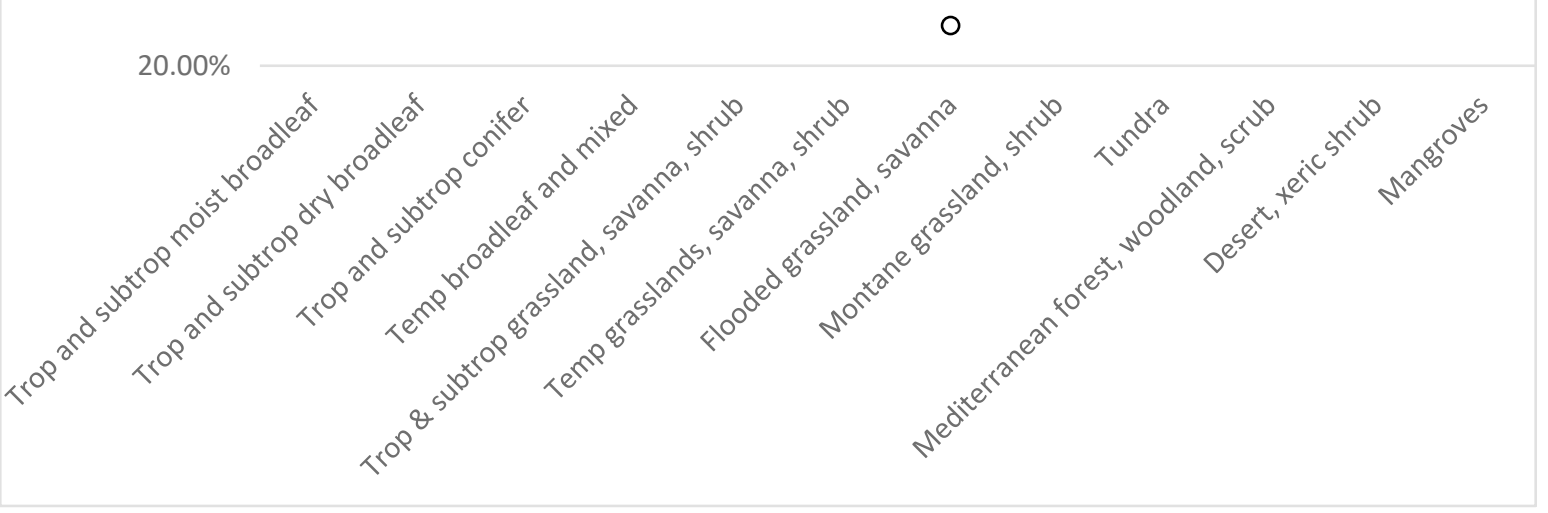


Table 4. The range of user selected FCl thresholds used in each biome for each sensor.

\begin{tabular}{|l|l|l|}
\hline Biome & PlanetScope Threshold Range & Sentinel-2 Threshold Range \\
\hline $\begin{array}{l}\text { Tropical and subtropical } \\
\text { moist broadleaf forest }\end{array}$ & $160-200$ & $98-280$ \\
\hline $\begin{array}{l}\text { Tropical and subtropical } \\
\text { dry broadleaf forest }\end{array}$ & $140-400$ & $99-509$ \\
\hline $\begin{array}{l}\text { Tropical and subtropical } \\
\text { coniferous forest }\end{array}$ & $80-190$ & $110-140$ \\
\hline $\begin{array}{l}\text { Temperate broadleaf and } \\
\text { mixed forest }\end{array}$ & $140-210$ & $65-180$ \\
\hline $\begin{array}{l}\text { Tropical and subtropical } \\
\text { grasslands, savannas and } \\
\text { shrublands }\end{array}$ & $130-240$ & $50-120$ \\
\hline $\begin{array}{l}\text { Temperate grasslands, } \\
\text { savannas and shrublands }\end{array}$ & $90-200$ & $60-115$ \\
\hline $\begin{array}{l}\text { Flooded grasslands and } \\
\text { savannas }\end{array}$ & $100-150$ & $90-130$ \\
\hline $\begin{array}{l}\text { Montane grasslands and } \\
\text { shrublands }\end{array}$ & $200-600$ & $30-185$ \\
\hline Rock and ice & $70-100$ & $25-90$ \\
\hline $\begin{array}{l}\text { Mediterranean forests, } \\
\text { woodlands and scrub }\end{array}$ & $160-380$ & $125-483$ \\
\hline $\begin{array}{l}\text { Deserts and xeric } \\
\text { shrublands }\end{array}$ & $230-320$ & $87-165$ \\
\hline Mangroves & $100-220$ & $55-115$ \\
\hline
\end{tabular}

Figure 5. Result of a PlanetScope image from the "tropical and subtropical moist broadleaf forest" biome showing: (a) a subset of the original image; (b) a grayscale raster showing $\mathrm{FCl}$ output; (c) the classified raster after the NDVI mask and $\mathrm{FCl}$ mask are applied, showing tree cover in green and non-tree cover in red; and (d) in the PlanetScope imagery only, the classified raster after sieve and clump smoothing algorithms are applied, showing tree cover in green and non-tree cover in red.

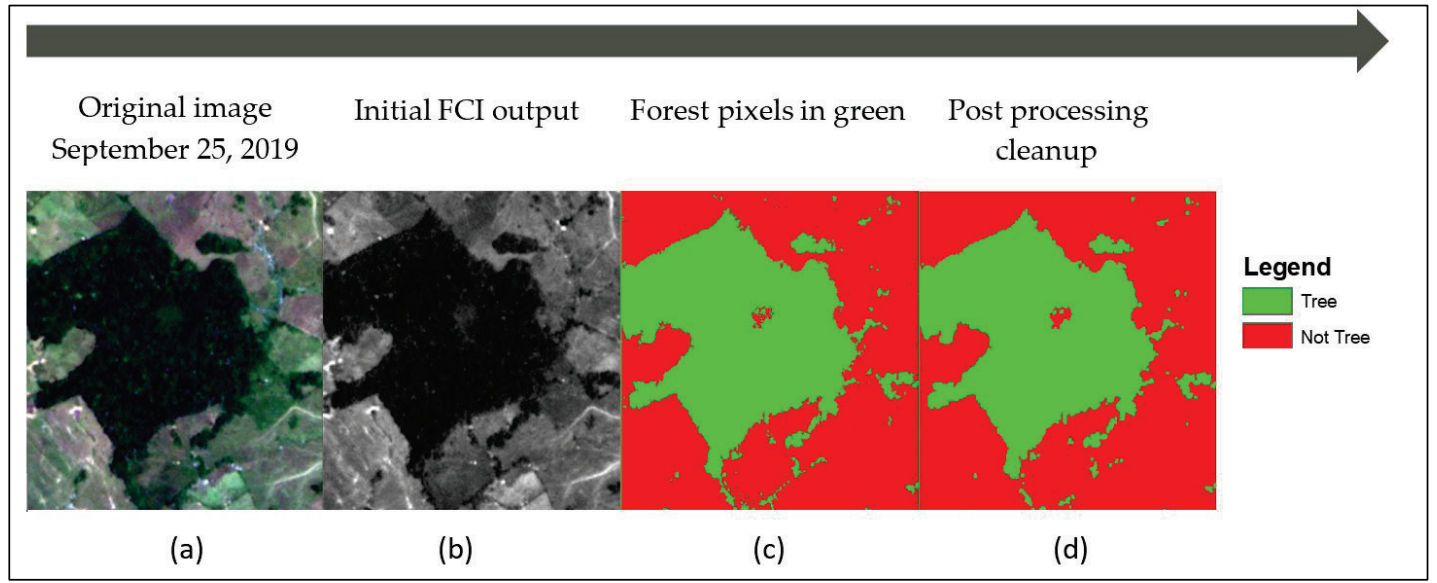


Figure 6. The $\mathrm{FCl}$ performed most accurately in images with dense tree canopy, such as during leaf-on seasons in tropical biomes, showing tree cover in green and non-tree cover in red. For example, in the "tropical and subtropical grasslands, savannas, and shrublands" and "tropical and subtropical dry broadleaf forest" biomes, both sensors achieve high accuracy.

Biome: Tropical and subtropical grasslands, savannas and shrublands

Sensor: Sentinel-2 Date: 2017-05-07

Kappa: $0.90 \quad$ Overall accuracy: $95 \%$

(a)

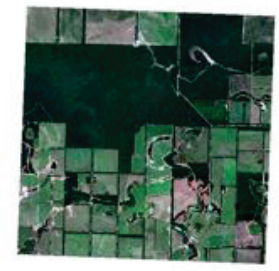

Sensor: PlanetScope

Kappa: 0.76
Date: 2019-04-18

Overall accuracy: $88 \%$

(b)
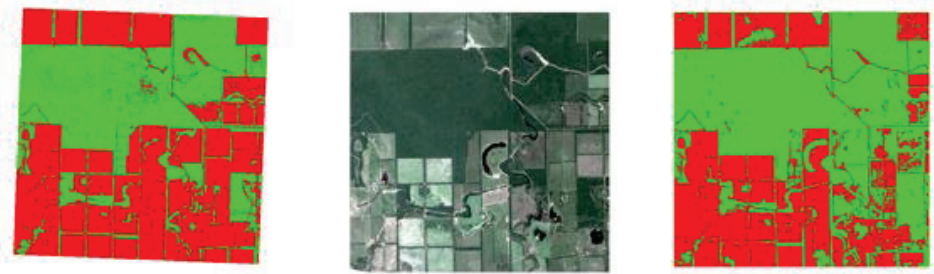

Legend

Biome: Tropical and subtropical dry broadleaf forest

Sensor: Sentinel-2 Date: 20190512

Kappa: $0.90 \quad$ Overall accuracy: $95 \%$

(c)

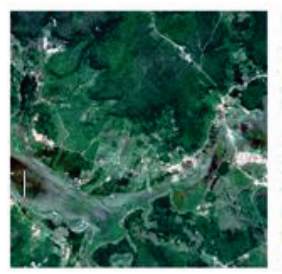

Sensor: PlanetScope Kappa: 0.84

(d)

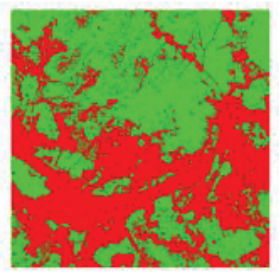

Date: 2019-01-30

Overall accuracy: $92 \%$
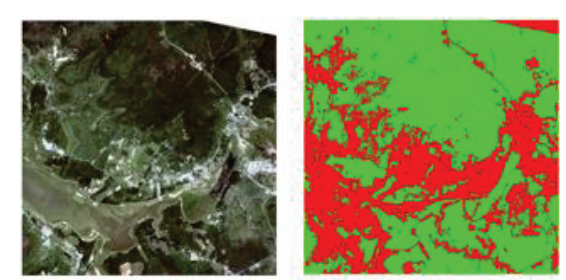
Figure 7. The $\mathrm{FCl}$ performed poorly in distinguishing trees from other land covers when trees were senescent, or wetlands were present. Sentinel-2 ( $a$ and $c$ ) and PlanetScope (b and d) imagery shows poor accuracy when senescent trees were present adjacent to a marshy reservoir ( $a$ and $c$ ) or tree cover grew alongside marshland ( $b$ and d). Tree cover is in green and non-tree cover in red.

Biome: Tropical and subtropical dry broadleaf forest

$\begin{array}{lll}\text { Sensor: Sentinel-2 } & \text { Date: } 2019-09-09 & \text { Sensor: PlanetScope Date: } 20190823 \\ \text { Kappa: } 0.42 & \text { Overall accuracy: } 71 \% & \text { Kappa: } 0.16 \quad \text { Overall accuracy: } 58 \%\end{array}$

(b)

(a)

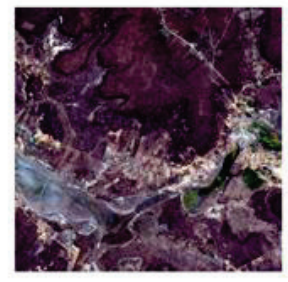

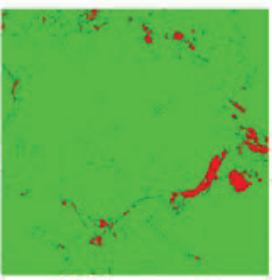
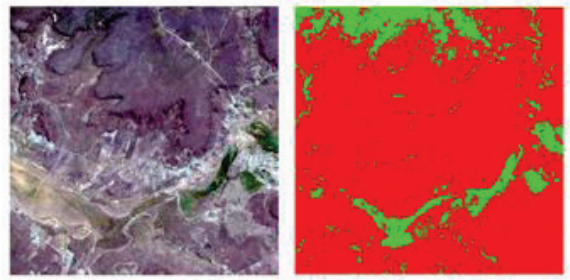

Legend

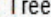

Biome: Mangroves

Sensor: Sentinel-2

Kappa: 0.22

(c)

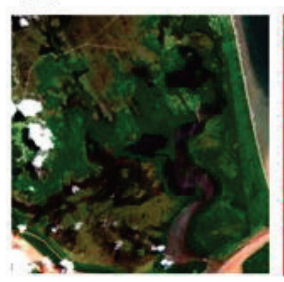

Date: 2017-07-15 Overall accuracy: $63 \%$

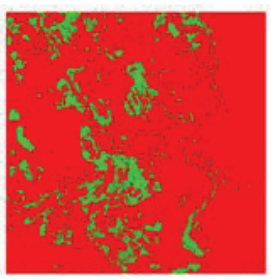

Sensor: PlanetScope Date: 20190703 Kappa: 0.46 Overall accuracy: $73 \%$

(d)

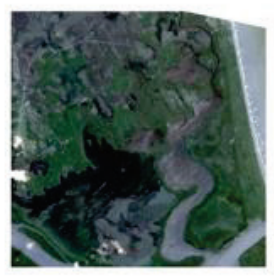

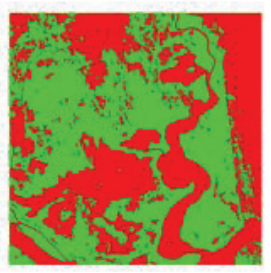

Kappa values ranged from 0.02 to 0.96 in PlanetScope and -0.18 to 0.94 in Sentinel-2 (Figure 3). Locations and dates where the Kappa statistic was 0.70 and above corresponded to an overall accuracy of $85 \%$ and above (see Appendix Tables A1 and A2). Kappa values above 0.70 included dates in all of the biomes except the "flooded grasslands and savannas" biome in PlanetScope and "Mediterranean forests, woodlands and scrub," and "mangroves" in Sentinel-2 imagery. The sites and dates where the FCI performed well contained higher overall tree cover and less snow than the biomes where accuracy was lower. The seasons and locations where the highest Kappa values occurred contain clear delineation between tree and non-tree areas (Figure 5) and fewer zones of transitional vegetation (Figure 6). However, this higher performance in delineated tree cover areas may be a result imagery interpretation, with large sections of trees being easier to identify for thresholding and allowing a better threshold fit. 
This potential user bias is difficult to remove from the process as it is currently designed and would affect the final Kappa scores.

Areas that performed poorly contained marshland alongside tree cover, senescent tree cover, and shadowing (see Figure 7). Prior research showed wetland vegetation and water can be misclassified by the FCI as tree cover because water has low reflectance values in the red band which are similar to the FCI values for dark tree cover (Becker et al. 2018). While senescent tree cover is likely spectrally distinct from non-tree vegetation in the same images, the NDVI mask removed these areas due to their lack of leaf canopy before an appropriate FCI threshold could be selected. Shadows, particularly in mountainous regions, were overclassified as tree cover due to low reflectance values, similar to water, and complicated both the selection of an appropriate threshold and validation by obscuring or distorting pixels.

In the individual error matrix of Kappa analysis, a Z-statistic of greater than 1.96 indicated the classification was better than a random classification (Table A2). In almost all sites and dates, the Z-statistic was greater than 1.96. The exceptions were in sites 2 and 6 in PlanetScope and sites 7 and 11 in Sentinel-2, which coincided to Kappa values below 0.24 and overall accuracies below $51 \%$. 


\section{Discussion}

The results support the FCI method as a tree cover classifier that 1) is usable in multiple globally distributed biomes under leaf-on conditions, 2) is simple to apply and interpret, and 3) does not require training data or difficult to acquire imagery. Tree cover classification was successful where there was a clear distinction between tree and ground cover with less dense, low, or no vegetation, including all of the tropical and subtropical biomes, "rock and ice," and "temperate broadleaf and mixed forest." This result corresponds with the land cover present at the Beltsville Agricultural Research Center site tested in prior research (Becker et al. 2018).

While there was no consistent difference in seasonal accuracy, perhaps due to the disparate nature of the biome conditions, seasonal changes such as flooding, snow, and tree senescence did reduce the accuracy of the FCI in specific images. This aligns with previous research by Becker et al. (2018) and Feliciano-Cruz et al. (2019) who found clear delineation with the FCI between tree cover and the other land covers in the image, including agriculture and built-up land, Becker et al. (2018) also found a seasonal component.

This research found that images where tree cover was clearly delineated from other vegetation and built-up land covers performed similar to Becker et al. (2018) and Feliciano-Cruz et al. (2019). This was apparent in the image from the tropical and subtropical grasslands, savannas and shrublands biome, which had clearly delineated tree cover alongside agriculture (Figure 6).

Accuracies were lower in comparison to Becker et al. (2018); however, Becker et al. (2018) only examined one study site and used a less robust non-random sampling accuracy assessment technique, which could have inflated their accuracy. The Kappa values of this research were consistent with the Kappa value that Feliciano-Cruz et al. (2019) derived from an error analysis using random sampling.

Results of this study align with literature evidence that water and snow cover interfere with vegetation spectral signatures (Clevers et al. 2010; Silva et al. 2008; Negi et al. 2009). Forest classification using the FCI was less successful in biomes characterized by transitional edges such as "Mediterranean forests, woodlands, and scrub," and "deserts and xeric 
shrublands.” FCI classification was also less accurate when tree cover was collocated with water or snow cover, as occurred in some seasons in the "flooded grasslands and savannas," "mangrove," and "tundra" biomes.

Additionally, mountainous scenes with strong shadowing reduced accuracy. In previous work, shadows distributed within the tree canopy were useful to differentiate tree cover (Becker et al. 2018; Feliciano-Cruz et al. 2019). Knipling (1970) showed that tree canopy has a low reflectance due to canopy reflectance and shadow. Shadowing within foliage, which is more likely to be more intense in tree canopy than less dense vegetation covers, may also contribute to spectral differences between tree cover and less dense vegetation as Zhang et al. (2015) showed that shadowing decreases the overall spectral curve. However, strong shadowing caused non-tree land cover to have low values, which were spectrally similar to dense vegetation and caused the FCI to misclassify these areas. This was consistent with prior research (Becker et al. 2018; Feliciano-Cruz et al. 2019).

Similar accuracy trends were observed between sensors. In some instances, accuracy was similar within each biome and within each season. More PlanetScope classification maps had Kappa greater than 0.70 than Sentinel-2, though this may be expected as PlanetScope has higher spatial resolution, capturing less spectral mixing and fewer land cover types in one pixel than happens with a larger pixel size. Additionally, the postprocessing smoothing steps applied to fill in speckling in groups classified as not-tree pixels and remove tree pixels in non-forested areas in PlanetScope could have contributed bias that slightly inflated accuracy.

\subsection{Limitations and recommendations for improvement}

Time and cost constraints limited exploration of the FCI application. Sample size was limited to one site per biome. A more robust sample size would clarify trends observed in this study. The impact of changing the NDVI from the fixed threshold of 0.4 to improve accuracy was not developed in this study due to time limitations. The 0.4 threshold was selected as an appropriate general value after limited exploratory visual analysis of $0.2-0.7$ thresholds. To improve the results, it is suggested to use a more robust sample size as well as testing manipulation of the NDVI and FCI thresholds. 
The FCI is not normalized as it is calculated with the brightness of the pixels in the image, which can vary substantially between images and across sensors. The temporal and sensor differences are also the main cause of variation in magnitude of FCI thresholds. These variations make it difficult to assign a standard range or universal FCI threshold.

Exploratory manipulation of NDVI and FCI thresholds was examined in additional imagery outside this study and yielded the following venues for further investigation. Scenes with dense, low-stature vegetation may benefit from stricter thresholds (higher NDVI, lower FCI) to restrict the selection to trees, which typically have more dense vegetation and thicker canopy. Scenes with sparse vegetation may benefit from more permissive thresholds (lower NDVI, higher FCI) because within a partially vegetated pixel, higher reflectance of the bare ground mixes with the vegetation signal (spectral mixing), causing an overall higher reflectance, which can lead to exclusion of target pixels with trees under the default thresholds. Similarly, snow cover and leaf-off deciduous trees may benefit from applying FCI without an NDVI mask as snow and leaf litter raise pixel values into NDVI exclusion. Wetland scenes and scenes with strong shadowing may benefit from a higher NDVI threshold as the FCI is likely to misclassify pixels with high absorbance / low reflectance such as wet or dark ground if they are not excluded by the NDVI mask.

Future research could also explore methods to automate the manual selection of an FCI threshold. Preliminary data exploration suggests three thresholding approaches that may have value for quick-assessment tools. The first approach would be to determine a global default estimate, capable of achieving minimally satisfactory tree identification. The second approach will use biome-specific default thresholds, optimized for specific environmental conditions. The third approach would input image histogram values into a global or biome specific regression equation to provide estimated thresholds that were sensitive to image values. Techniques using histograms to threshold have been employed in prior research (Ramos-Bernal et al. 2018). Once the threshold estimation has been automated, future work could incorporate the FCI output in comparative research. The FCI can be validated against existing tree cover maps (Hansen et al. 2013). The FCI can additionally be used to subset training data that can support supervised machine learning classifiers such as Support Vector Machine or Random Forest. 


\section{Conclusions}

This research expanded studies by Becker et al. (2018) and Feliciano et al. (2019) to apply the FCI to seasonal MSI in 12 biomes and found it to be successful in identifying tree covers under certain environmental conditions. The FCI can aid in remotely identifying tree cover for a variety of civil and military operations that depend on timely and accurate land cover classification. This index is simple to apply and interpret, uses common MSI from a variety of sensors, and can be executed with limited computing and time resources, avoiding reliance on training data, complex and computationally heavy algorithms, or imagery that are expensive to acquire. Future research will focus in automating identification of the FCI and NDVI thresholds that separates trees from other land covers and use of FCI output as training data for machine learning operations. 


\section{References}

Akar, A., E. Gokalp, O. Akar, and V. Yilmaz. 2017. "Improving classification accuracy of spectrally similar land covers in the rangeland and plateau areas with a combination of WorldView-2 and UAV images.” Geocarto Int., 32(9): 990-1003.

Becker, S. J., C. S. T. Daughtry, and A. L. Russ. 2018. "Robust forest cover indices for multispectral images.” Photogramm. Eng. \& Remote Sens., 84(8): 505-512.

Bunting, P. L. R. 2006. "The delineation of tree crowns in Australian mixed species forests using Compact Airborne Spectrographic Imager (CASI) data." Remote Sens. of Env., 101(2): 230-248.

Chen, J. M. 1996. "Evaluation of vegetation indices and a modified simple ratio for boreal applications.” Can. J. of Remote Sens., 22(3): 229-242.

Chen, Q., D. Baldocchi, P. Gong, and M. Kelly. 2006. "Isolating individual trees in a savanna woodland using small footprint lidar data." Photogramm. Eng. \& Remote Sens., 72(8): 923-932.

Clevers, J., L. Kooistra, and M. Schaepman. 2010. "Estimating canopy water content using hyperspectral remote sensing data." Int. J. of Applied Earth Observation and Geoinformation, 12(2) 119-125.

Congalton, R. G. 1991. "A review of assessing the accuracy of classifications of remotely sensed data." Remote Sens. of Env., 37(1): 35-46.

Congalton, R. G., and K. Green. 2008. Assessing the Accuracy of Remotely Sensed Data: Principles and Practices, Second Edition, New York: CRC Press.

Congalton, R. G., R. Oderwald, and R. Mead. 1983. "Assessing Landsat classification accuracy using discrete multivariate analysis statistical techniques."

Photogramm. Eng. and Remote Sens., 49(12): 1671-1678.

Dinerstein, E., D. Olson, A. Joshi, C. Vynne, N. Burgess, E. Wikramanayake, N. Hahn, S. Palminteri, P. Hedao, R. Noss, M. Hansen, H. Locke, E. C. Ellis, B. Jones, C. V. Barber, R. Hayes, C. Kormos, V. Martin, E. Crist, W. Sechrest, L. Price, J. E. M. Baillie, D. Weeden, K. Suckling, C. Davis, N. Sizer, R. Moore, D. Thau, T. Birch, P. Potapov, S. Turubanova, A. Tyukavina, N. de Souza, L. Pintea, J. C. Brito, O. A. Llewellyn, A. G. Miller, A. Patzelt, S. A. Ghazanfar, J. Timberlake, H. Kloser, Y. Shennan-Farpon, R. Kindt, J. B. Lilleso, P. van Breugel, L. Graudal, M. Voge, K. F. Al-Shammari, and M. Saleem. 2017. "An ecoregion-based approach to protecting half the terrestrial realm." BioSci., 67(6): 534-545.

European Space Agency. 2020. "Copernicus Open Access." [Online]. Available: https://scihub.copernicus.eu/dhus/.

Feliciano-Cruz, L. I., S. J. Becker, K. D. Lasko, C. S. T. Daughtry, and A. L. Russ. 2019. Forest Cover Index for tree cover detection using Landsat-7 multispectral imagery. Alexandria, VA: U.S. Army Engineer Research and Development Center, ERDC/GRL TR-19-1. 
Fu, L., L. Zhang, and C. He. 2014. "Analysis of agricultural land use change in the middle reach of the Heihe River Basin, Northwest China.” Int. Journal of Env. Res. and Public Health, 11(3): 2698-2712.

Graves, S. J., G. P. Asner, R. E. Martin, C. B. Anderson, M. S. Colgan, L. Kalantari, and S. A. Bohlman. 2016. "Tree species abundance predictions in a tropical agricultural landscape with a supervised classification model and imbalanced data." Remote Sens., 8: 161.

Hansen, M. C., P. V. Potapov, R. Moore, M. Hancher, S. A. Turubanova, A. Tuyukavina, D. Thau, S. V. Stehman, S. J. Goetz, T. R. Loveland, A. Kommareddy, A. Egorov, L. Chini, C. O. Justice, and J. R. G. Townshend. 2013. "High-resolution global maps of 21st-century forest cover change.” Sci., 342(6160): 850-853.

Heckel, K., M. Urban, P. Schratz, M. D. Mahecha, and C. Schmullius. 2020. "Predicting forest cover in distinct ecosystems: The potential of multi-source Sentinel-1 and 2 data fusion." Remote Sens., 12: 302.

Jiang, Z., A. Huete, K. Didan, and T. Miura. 2008. "Development of a two-band enhanced vegetation index without a blue band." Remote Sens. of Env., 112(10): 38333845 .

Ke, Y., and L. Quackenbush. 2011. "A review of methods for automatic individual treecrown detection and delineation from passive remote sensing." Int. J. of Remote Sens., 32(17): 4725-4747.

Knipling, E. 1970. "Physical and physiological basis for the reflectance of visible and nearinfrared radiation from vegetation." Remote Sens. of Env., 1(3): 155-159.

Knipling, E. 1970. "Physical and physiological basis for the reflectance of visible and nearinfrared radiation from vegetation." Remote Sens. of Env., 1(3): 155-159.

Kumar, A., and N. Sinha. 2020. "Classification of forest cover type using random forests algorithm. Advances in Data and Information Scie., Singapore, Springer Singapore, pp. 395-402.

Loveland, T. R., B. C. Reed, J. F. Brown, D. O. Ohlen, Z. Zhu, L. Yang, and J. W. Merchant. 2000. "Development of a global land cover characteristics database and IGBP DISCover from 1 km AVHRR data.” Int. J. of Remote Sens., 21(6 \& 7): 1303-1330.

Negi, H., A. Kulkarni, and B. Semwal. 2009. "Study of contaminated and mixed objects snow reflectance in Indian Himalaya using spectroradiometer.” Int. J. of Remote Sens., 30(2): 315-325.

Olson, D. M., E. Dinerstein, E. D. Wikramanayake, N. D. Burgess, G. V. N. Powell, E. C. Underwood, J. A. D'amico, I. Itoua, H. E. Strand, J. C. Morrison, C. J. Loucks, T. F. Allnutt, T. H. Ricketts, Y. Kura, J. F. Lamoreux, W. W. Wettengel, P. Hedao, and K. R. Kassem. 2001. "Terrestrial Ecoregions of the World: A New Map of Life on Earth: A new global map of terrestrial ecoregions provides an innovative tool for conserving biodiversity." BioSci., 51(11): 933-938. 
Pitkanen, J. 2001. "Individual tree detection in digital aerial images by combining locally adaptive binarization and local maxima methods." Can. J. of Forest Res., 31(5): 832-844.

Planet Team. 2017. "Planet Application Program Interface: In Space for Life on Earth." [Online]. Available: https://api.planet.com..

Pouliot, D., D. King, F. Bell, and D. Pitt. 2002. "Automated tree crown detection and delineation in high-resolution digital camera imagery of coniferous forest regeneration." Remote Sens. of Env., 82(2): 322-334.

Ramos-Bernal, R. N., R. Vázquez-Jiménez, R. Romero-Calcerrada, P. Arrogante-Funes, and C. J. Novillo. 2018. "Evaluation of unsupervised change detection methods applied to landslide inventory mapping using ASTER imagery.” Remote Sens., 10(12): 1987.

Richardson, A. J., and C. L. Wiegand. 1977. "Distinguishing vegetation from soil background information.” Photogramm. Eng. \& Remote Sens., 43(12): 15411552.

Rouse, J. W. 1973. Monitoring the vernal advancement and retrogradation (green wave effect) of natural vegetation. College Station, TX: Texas A\&M University, Remote Sens. Center.

Silva, T. S. F., M. P. F. Costa, J. M. Melack, and E. L. M. Novo. 2008. "Remote sensing of aquatic vegetation: theory and applications.” Environ Monit Assess, 140(1-3): 131-145.

Story, M., and R. G. Congalton. 1986. “Accuracy assessment: a user's perspective.” Photogramm. Eng. and Remote Sens., 52(3): 397-399.

Tucker, C. J. 1979. "Red and photographic infrared linear combinations for monitoring vegetation." Remote Sens. of Env., 8(2): 127-150.

Wu, M. F., Z. C. Sun, B. Yang, and S. S. Yu. 2017. "Synergistic use of WorldView-2 imagery and airborne LiDAR data for urban land cover classification." IOP Conf. Series: Earth and Env. Sci., 57.

Ye, W., X. Li, X. Chen, and G. Zhang. 2014. A spectral index for highlighting forest cover from remotely sensed imagery, in Proceedings of SPIE - The Int. Society for Optical Eng., Beijing, China.

Yuan, F., K. E. Sawaya, B. C. Loeffelholz, and M. E. Bauer. 2005. "Land cover classification and change analysis of the Twin Cities (Minnesota) Metropolitan Area by multitemporal Landsat remote sensing." Remote Sens. of Env., 98(2-3): 317-328.

Zhang, L., X. Sun, T. Wu, and H. Zhang. 2015. "An analysis of shadow effects on spectral vegetation indexes using a ground-based imaging spectrometer.” IEEE Geosci. and Remote Sens. Letters, 12(11): 2188-2192.

Zhu, Z., and D. L. Evans. 1994. "U.S. Forest Types and Predicted Percent Forest Cover from AVHRR Data.” Photogramm. Eng. \& Remote Sens., 60(5): 525-531. 


\section{Appendix A}

Table A1. Producer's, user's, and overall accuracy for Tree versus Not Tree classifications for the FCl in PlanetScope and Sentinel-2 imagery for each date and biome.

\begin{tabular}{|c|c|c|c|c|c|c|c|c|c|c|}
\hline \multicolumn{6}{|c|}{ PlanetScope } & \multicolumn{5}{|l|}{ Sentinel-2 } \\
\hline Site ID & Date & Class & $\begin{array}{l}\text { Producer's } \\
\text { Accuracy } \\
\text { (\%) }\end{array}$ & $\begin{array}{l}\text { User's } \\
\text { Accuracy } \\
\text { (\%) }\end{array}$ & $\begin{array}{l}\text { Overall } \\
\text { Accuracy } \\
\text { (\%) }\end{array}$ & Date & Class & $\begin{array}{l}\text { Producer's } \\
\text { Accuracy } \\
(\%)\end{array}$ & $\begin{array}{l}\text { User's } \\
\text { Accuracy } \\
\text { (\%) }\end{array}$ & $\begin{array}{l}\text { Overall } \\
\text { Accuracy } \\
(\%)\end{array}$ \\
\hline \multirow[t]{11}{*}{01} & \multirow[t]{2}{*}{20180925} & Tree & 95.74 & 90.00 & 93.00 & \multirow[t]{2}{*}{20190926} & Tree & 89.29 & 100.00 & 94.00 \\
\hline & & $\begin{array}{l}\text { Not } \\
\text { Tree }\end{array}$ & 90.57 & 96.00 & & & Not Tree & 100.00 & 88.00 & \\
\hline & & & & & & & & & & \\
\hline & \multirow[t]{2}{*}{20181018} & Tree & 92.68 & 76.00 & 85.00 & \multirow[t]{2}{*}{20181230} & Tree & 95.83 & 92.00 & 94.00 \\
\hline & & $\begin{array}{l}\text { Not } \\
\text { Tree }\end{array}$ & 79.66 & 94.00 & & & Not Tree & 92.31 & 96.00 & \\
\hline & & & & & & & & & & \\
\hline & \multirow[t]{2}{*}{20180621} & Tree & 86.67 & 52.00 & 72.00 & \multirow[t]{2}{*}{20180213} & Tree & 82.61 & 76.00 & 80.00 \\
\hline & & $\begin{array}{l}\text { Not } \\
\text { Tree }\end{array}$ & 65.71 & 92.00 & & & Not Tree & 77.78 & 84.00 & \\
\hline & & & & & & & & & & \\
\hline & \multirow[t]{2}{*}{20180831} & Tree & 94.12 & 64.00 & 80.00 & \multirow[t]{2}{*}{20190404} & Tree & 57.14 & 94.12 & 74.00 \\
\hline & & $\begin{array}{l}\text { Not } \\
\text { Tree }\end{array}$ & 72.73 & 96.00 & & & Not Tree & 95.45 & 63.64 & \\
\hline \multirow[t]{10}{*}{02} & \multirow[t]{2}{*}{20191030} & Tree & 71.21 & 94.00 & 78.00 & \multirow[t]{2}{*}{20181024} & Tree & 95.65 & 88.00 & 91.92 \\
\hline & & $\begin{array}{l}\text { Not } \\
\text { Tree }\end{array}$ & 91.18 & 62.00 & & & Not Tree & 88.68 & 95.95 & \\
\hline & & & & & & & & & & \\
\hline & \multirow[t]{2}{*}{20190130} & Tree & 97.73 & 86.00 & 92.00 & \multirow[t]{2}{*}{20190122} & Tree & 87.72 & 100.00 & 93.00 \\
\hline & & $\begin{array}{l}\text { Not } \\
\text { Tree }\end{array}$ & 87.50 & 98.00 & & & Not Tree & 100.00 & 86.00 & \\
\hline & & & & & & & & & & \\
\hline & \multirow[t]{2}{*}{20190512} & Tree & 89.58 & 86.00 & 88.00 & \multirow[t]{2}{*}{20190512} & Tree & 92.45 & 98.00 & 95.00 \\
\hline & & $\begin{array}{l}\text { Not } \\
\text { Tree }\end{array}$ & 86.54 & 90.00 & & & Not Tree & 97.87 & 92.00 & \\
\hline & \multirow[t]{2}{*}{20190823} & Tree & 57.14 & 64.00 & 58.00 & \multirow{2}{*}{20190909} & Tree & 100.00 & 42.00 & 71.00 \\
\hline & & $\begin{array}{l}\text { Not } \\
\text { Tree }\end{array}$ & 59.09 & 52.00 & & & Not Tree & 63.29 & 100.00 & \\
\hline \multirow[t]{2}{*}{03} & \multirow{2}{*}{20181214} & Tree & 75.38 & 98.00 & 83.00 & \multirow{2}{*}{20171009} & Tree & 72.73 & 96.00 & 80.00 \\
\hline & & $\begin{array}{l}\text { Not } \\
\text { Tree }\end{array}$ & 97.14 & 68.00 & & & Not Tree & 94.12 & 64.00 & \\
\hline
\end{tabular}




\begin{tabular}{|c|c|c|c|c|c|c|c|c|c|c|}
\hline \multicolumn{6}{|c|}{ PlanetScope } & \multicolumn{5}{|l|}{ Sentinel-2 } \\
\hline \multirow[t]{8}{*}{ Site ID } & Date & Class & $\begin{array}{l}\text { Producer's } \\
\text { Accuracy } \\
\text { (\%) }\end{array}$ & $\begin{array}{l}\text { User's } \\
\text { Accuracy } \\
(\%)\end{array}$ & $\begin{array}{l}\text { Overall } \\
\text { Accuracy } \\
(\%)\end{array}$ & Date & Class & $\begin{array}{l}\text { Producer's } \\
\text { Accuracy } \\
\text { (\%) } \\
\end{array}$ & $\begin{array}{l}\text { User's } \\
\text { Accuracy } \\
(\%)\end{array}$ & $\begin{array}{l}\text { Overall } \\
\text { Accuracy } \\
(\%)\end{array}$ \\
\hline & \multirow{2}{*}{20190315} & Tree & 88.24 & 90.00 & 89.00 & \multirow{2}{*}{20181203} & Tree & 100.00 & 88.00 & 94.00 \\
\hline & & $\begin{array}{l}\text { Not } \\
\text { Tree }\end{array}$ & 89.80 & 88.00 & & & Not Tree & 89.29 & 100.00 & \\
\hline & \multirow[t]{2}{*}{20190414} & Tree & 83.05 & 98.00 & 89.00 & \multirow[t]{2}{*}{20190313} & Tree & 92.31 & 96.00 & 94.00 \\
\hline & & $\begin{array}{l}\text { Not } \\
\text { Tree }\end{array}$ & 97.56 & 80.00 & & & Not Tree & 95.83 & 92.00 & \\
\hline & & & & & & & & & & \\
\hline & \multirow[t]{2}{*}{20190726} & Tree & 80.70 & 92.00 & 85.00 & \multirow[t]{2}{*}{20180701} & Tree & 79.03 & 98.00 & 86.00 \\
\hline & & $\begin{array}{l}\text { Not } \\
\text { Tree }\end{array}$ & 90.70 & 78.00 & & & Not Tree & 97.37 & 74.00 & \\
\hline \multirow[t]{11}{*}{04} & \multirow[t]{2}{*}{20191116} & Tree & 92.31 & 96.00 & 94.00 & \multirow[t]{2}{*}{20191118} & Tree & 89.29 & 100.00 & 94.00 \\
\hline & & $\begin{array}{l}\text { Not } \\
\text { Tree }\end{array}$ & 95.83 & 92.00 & & & Not Tree & 100.00 & 88.00 & \\
\hline & & & & & & & & & & \\
\hline & \multirow[t]{2}{*}{20190126} & Tree & 94.12 & 96.00 & 95.00 & \multirow[t]{2}{*}{20190412} & Tree & 84.48 & 98.00 & 90.00 \\
\hline & & $\begin{array}{l}\text { Not } \\
\text { Tree }\end{array}$ & 95.92 & 94.00 & & & Not Tree & 97.62 & 82.00 & \\
\hline & & & & & & & & & & \\
\hline & \multirow[t]{2}{*}{20190418} & Tree & 95.24 & 80.00 & 88.00 & \multirow[t]{2}{*}{20170507} & Tree & 92.45 & 98.00 & 95.00 \\
\hline & & $\begin{array}{l}\text { Not } \\
\text { Tree }\end{array}$ & 82.76 & 96.00 & & & Not Tree & 97.87 & 92.00 & \\
\hline & & & & & & & & & & \\
\hline & \multirow[t]{2}{*}{20190914} & Tree & 85.71 & 96.00 & 90.00 & \multirow[t]{2}{*}{20190909} & Tree & 96.08 & 98.00 & 97.00 \\
\hline & & $\begin{array}{l}\text { Not } \\
\text { Tree }\end{array}$ & 95.45 & 84.00 & & & Not Tree & 97.96 & 96.00 & \\
\hline \multirow[t]{8}{*}{05} & \multirow[t]{2}{*}{20191111} & Tree & 95.65 & 88.00 & 92.00 & \multirow[t]{2}{*}{20191123} & Tree & 94.23 & 98.00 & 96.00 \\
\hline & & $\begin{array}{l}\text { Not } \\
\text { Tree }\end{array}$ & 88.89 & 96.00 & & & Not Tree & 97.92 & 94.00 & \\
\hline & & & & & & & & & & \\
\hline & \multirow[t]{2}{*}{20181224} & Tree & 91.11 & 82.00 & 87.00 & \multirow[t]{2}{*}{20171218} & Tree & 83.05 & 98.00 & 89.00 \\
\hline & & $\begin{array}{l}\text { Not } \\
\text { Tree }\end{array}$ & 83.64 & 92.00 & & & Not Tree & 97.56 & 80.00 & \\
\hline & \multirow{3}{*}{20190422} & & & & & & & & & \\
\hline & & Tree & 85.19 & 92.00 & 88.00 & \multirow{2}{*}{20180522} & Tree & 79.03 & 98.00 & 86.00 \\
\hline & & $\begin{array}{l}\text { Not } \\
\text { Tree }\end{array}$ & 91.30 & 84.00 & & & Not Tree & 97.37 & 74.00 & \\
\hline
\end{tabular}




\begin{tabular}{|c|c|c|c|c|c|c|c|c|c|c|}
\hline \multicolumn{6}{|c|}{ PlanetScope } & \multicolumn{5}{|l|}{ Sentinel-2 } \\
\hline \multirow[t]{3}{*}{ Site ID } & Date & Class & $\begin{array}{l}\text { Producer's } \\
\text { Accuracy } \\
\text { (\%) }\end{array}$ & $\begin{array}{l}\text { User's } \\
\text { Accuracy } \\
(\%)\end{array}$ & $\begin{array}{l}\text { Overall } \\
\text { Accuracy } \\
(\%)\end{array}$ & Date & Class & $\begin{array}{l}\text { Producer's } \\
\text { Accuracy } \\
(\%)\end{array}$ & $\begin{array}{l}\text { User's } \\
\text { Accuracy } \\
(\%)\end{array}$ & $\begin{array}{l}\text { Overall } \\
\text { Accuracy } \\
(\%)\end{array}$ \\
\hline & \multirow[t]{2}{*}{20190826} & Tree & 100.00 & 84.00 & 92.00 & \multirow[t]{2}{*}{20190820} & Tree & 92.45 & 98.00 & 95.00 \\
\hline & & $\begin{array}{l}\text { Not } \\
\text { Tree }\end{array}$ & 86.21 & 100.00 & & & Not Tree & 97.87 & 92.00 & \\
\hline \multirow[t]{10}{*}{06} & \multirow[t]{2}{*}{20191116} & Tree & 52.94 & 18.00 & 51.00 & \multirow[t]{2}{*}{20191118} & Tree & 93.18 & 82.00 & 88.00 \\
\hline & & $\begin{array}{l}\text { Not } \\
\text { Tree }\end{array}$ & 50.60 & 84.00 & & & Not Tree & 83.93 & 94.00 & \\
\hline & & & & & & & & & & \\
\hline & \multirow[t]{2}{*}{20190130} & Tree & 93.10 & 54.00 & 75.00 & \multirow[t]{2}{*}{20190201} & Tree & 100.00 & 80.00 & 90.00 \\
\hline & & $\begin{array}{l}\text { Not } \\
\text { Tree }\end{array}$ & 67.61 & 96.00 & & & Not Tree & 83.33 & 100.00 & \\
\hline & & & & & & & & & & \\
\hline & \multirow[t]{2}{*}{20190506} & Tree & 54.55 & 12.00 & 51.00 & \multirow[t]{2}{*}{20190517} & Tree & 87.18 & 68.00 & 79.00 \\
\hline & & $\begin{array}{l}\text { Not } \\
\text { Tree }\end{array}$ & 50.56 & 90.00 & & & Not Tree & 73.77 & 90.00 & \\
\hline & \multirow{2}{*}{20190804} & Tree & 87.50 & 28.00 & 62.00 & \multirow{2}{*}{20190805} & Tree & 96.00 & 48.00 & 73.00 \\
\hline & & $\begin{array}{l}\text { Not } \\
\text { Tree }\end{array}$ & 57.14 & 96.00 & & & Not Tree & 65.33 & 98.00 & \\
\hline & & & & & & & & & & \\
\hline \multirow[t]{10}{*}{07} & \multirow[t]{2}{*}{20191022} & Tree & 92.00 & 92.00 & 92.00 & \multirow[t]{2}{*}{20191102} & Tree & 74.24 & 98.00 & 82.00 \\
\hline & & $\begin{array}{l}\text { Not } \\
\text { Tree }\end{array}$ & 92.00 & 92.00 & & & Not Tree & 97.06 & 66.00 & \\
\hline & & & & & & & & & & \\
\hline & \multirow[t]{2}{*}{20190304} & Tree & 100.00 & 56.00 & 78.00 & \multirow[t]{2}{*}{20190220} & Tree & 21.28 & 20.00 & 23.00 \\
\hline & & $\begin{array}{l}\text { Not } \\
\text { Tree }\end{array}$ & 69.44 & 100.00 & & & Not Tree & 26.53 & 26.00 & \\
\hline & \multirow[t]{2}{*}{20190408} & Tree & 90.24 & 74.00 & 83.00 & \multirow[t]{2}{*}{20190630} & Tree & 88.68 & 94.00 & 85.00 \\
\hline & & $\begin{array}{l}\text { Not } \\
\text { Tree }\end{array}$ & 77.97 & 92.00 & & & Not Tree & 92.68 & 76.00 & \\
\hline & & & & & & & & & & \\
\hline & \multirow[t]{2}{*}{20190810} & Tree & 90.91 & 80.00 & 86.00 & \multirow[t]{2}{*}{20190913} & Tree & 88.24 & 90.00 & 89.00 \\
\hline & & $\begin{array}{l}\text { Not } \\
\text { Tree }\end{array}$ & 82.14 & 92.00 & & & Not Tree & 89.80 & 88.00 & \\
\hline \multirow[t]{2}{*}{08} & \multirow[t]{2}{*}{20191015} & Tree & 83.05 & 98.00 & 89.00 & \multirow[t]{2}{*}{20191109} & Tree & 4.00 & 90.00 & 89.00 \\
\hline & & $\begin{array}{l}\text { Not } \\
\text { Tree }\end{array}$ & 97.56 & 80.00 & & & Not Tree & 89.80 & 88.00 & \\
\hline
\end{tabular}




\begin{tabular}{|c|c|c|c|c|c|c|c|c|c|c|}
\hline \multicolumn{6}{|c|}{ PlanetScope } & \multicolumn{5}{|l|}{ Sentinel-2 } \\
\hline \multirow[t]{8}{*}{ Site ID } & Date & Class & $\begin{array}{l}\text { Producer's } \\
\text { Accuracy } \\
\text { (\%) }\end{array}$ & $\begin{array}{l}\text { User's } \\
\text { Accuracy } \\
(\%)\end{array}$ & $\begin{array}{l}\text { Overall } \\
\text { Accuracy } \\
(\%)\end{array}$ & Date & Class & $\begin{array}{l}\text { Producer's } \\
\text { Accuracy } \\
\text { (\%) } \\
\end{array}$ & $\begin{array}{l}\text { User's } \\
\text { Accuracy } \\
(\%)\end{array}$ & $\begin{array}{l}\text { Overall } \\
\text { Accuracy } \\
(\%)\end{array}$ \\
\hline & \multirow{2}{*}{20190203} & Tree & 94.34 & 100.00 & 97.00 & \multirow{2}{*}{20190423} & Tree & 83.33 & 81.63 & 82.83 \\
\hline & & $\begin{array}{l}\text { Not } \\
\text { Tree }\end{array}$ & 100.00 & 94.00 & & & Not Tree & 82.35 & 84.00 & \\
\hline & \multirow[t]{2}{*}{20190508} & Tree & 77.78 & 98.00 & 85.00 & \multirow[t]{2}{*}{20180715} & Tree & 84.48 & 98.00 & 90.00 \\
\hline & & $\begin{array}{l}\text { Not } \\
\text { Tree }\end{array}$ & 97.30 & 72.00 & & & Not Tree & 97.62 & 82.00 & \\
\hline & & & & & & & & & & \\
\hline & \multirow[t]{2}{*}{20190823} & Tree & 85.96 & 98.00 & 91.00 & & & & & \\
\hline & & $\begin{array}{l}\text { Not } \\
\text { Tree }\end{array}$ & 97.67 & 84.00 & & & & & & \\
\hline \multirow[t]{11}{*}{09} & \multirow[t]{2}{*}{20191108} & Tree & 61.19 & 83.67 & 65.66 & \multirow[t]{2}{*}{20191110} & Tree & 77.05 & 94.00 & 83.00 \\
\hline & & $\begin{array}{l}\text { Not } \\
\text { Tree }\end{array}$ & 75.00 & 48.00 & & & Not Tree & 92.31 & 72.00 & \\
\hline & & & & & & & & & & \\
\hline & \multirow[t]{2}{*}{20190226} & Tree & 79.63 & 86.00 & 82.00 & \multirow[t]{2}{*}{20190305} & Tree & 64.94 & 100.00 & 73.00 \\
\hline & & $\begin{array}{l}\text { Not } \\
\text { Tree }\end{array}$ & 84.78 & 78.00 & & & Not Tree & 100.00 & 46.00 & \\
\hline & & & & & & & & & & \\
\hline & \multirow[t]{2}{*}{20190522} & Tree & 80.00 & 88.00 & 83.00 & \multirow[t]{2}{*}{20190519} & Tree & 70.00 & 98.00 & 78.00 \\
\hline & & $\begin{array}{l}\text { Not } \\
\text { Tree }\end{array}$ & 86.67 & 78.00 & & & Not Tree & 96.67 & 58.00 & \\
\hline & & & & & & & & & & \\
\hline & \multirow[t]{2}{*}{20190901} & Tree & 95.35 & 82.00 & 89.00 & \multirow[t]{2}{*}{20190807} & Tree & 62.16 & 92.00 & 68.00 \\
\hline & & $\begin{array}{l}\text { Not } \\
\text { Tree }\end{array}$ & 84.21 & 96.00 & & & Not Tree & 84.62 & 44.00 & \\
\hline \multirow[t]{8}{*}{10} & \multirow[t]{2}{*}{20191028} & Tree & 97.92 & 94.00 & 96.00 & \multirow[t]{2}{*}{20190211} & Tree & 61.73 & 100.00 & 69.00 \\
\hline & & $\begin{array}{l}\text { Not } \\
\text { Tree }\end{array}$ & 94.23 & 98.00 & & & Not Tree & 100.00 & 38.00 & \\
\hline & & & & & & & & & & \\
\hline & \multirow[t]{2}{*}{20190204} & Tree & 65.33 & 98.00 & 73.00 & \multirow[t]{2}{*}{20190412} & Tree & 68.06 & 98.00 & 75.00 \\
\hline & & $\begin{array}{l}\text { Not } \\
\text { Tree }\end{array}$ & 96.00 & 48.00 & & & Not Tree & 96.30 & 52.00 & \\
\hline & & & & & & & & & & \\
\hline & \multirow[t]{2}{*}{20190518} & Tree & 73.02 & 92.00 & 79.00 & \multirow[t]{2}{*}{20190719} & Tree & 83.64 & 92.00 & 86.73 \\
\hline & & $\begin{array}{l}\text { Not } \\
\text { Tree }\end{array}$ & 89.19 & 66.00 & & & Not Tree & 90.70 & 81.25 & \\
\hline
\end{tabular}




\begin{tabular}{|c|c|c|c|c|c|c|c|c|c|c|}
\hline \multicolumn{6}{|c|}{ PlanetScope } & \multicolumn{5}{|l|}{ Sentinel-2 } \\
\hline \multirow[t]{3}{*}{ Site ID } & Date & Class & $\begin{array}{l}\text { Producer's } \\
\text { Accuracy } \\
\text { (\%) }\end{array}$ & $\begin{array}{l}\text { User's } \\
\text { Accuracy } \\
(\%)\end{array}$ & $\begin{array}{l}\text { Overall } \\
\text { Accuracy } \\
(\%)\end{array}$ & Date & Class & $\begin{array}{l}\text { Producer's } \\
\text { Accuracy } \\
(\%) \\
\end{array}$ & $\begin{array}{l}\text { User's } \\
\text { Accuracy } \\
(\%)\end{array}$ & $\begin{array}{l}\text { Overall } \\
\text { Accuracy } \\
(\%)\end{array}$ \\
\hline & \multirow[t]{2}{*}{20190830} & Tree & 92.16 & 94.00 & 93.00 & \multirow[t]{2}{*}{20190909} & Tree & 73.44 & 94.00 & 80.00 \\
\hline & & $\begin{array}{l}\text { Not } \\
\text { Tree }\end{array}$ & 93.88 & 92.00 & & & Not Tree & 91.67 & 66.00 & \\
\hline \multirow[t]{10}{*}{11} & \multirow[t]{2}{*}{20190927} & Tree & 84.85 & 56.00 & 73.00 & \multirow[t]{2}{*}{20181202} & Tree & 40.43 & 38.00 & 41.00 \\
\hline & & $\begin{array}{l}\text { Not } \\
\text { Tree }\end{array}$ & 67.16 & 90.00 & & & Not Tree & 41.51 & 44.00 & \\
\hline & & & & & & & & & & \\
\hline & \multirow[t]{2}{*}{20190225} & Tree & 100.00 & 46.00 & 73.00 & \multirow[t]{2}{*}{20190116} & Tree & 65.85 & 54.00 & 51.00 \\
\hline & & $\begin{array}{l}\text { Not } \\
\text { Tree }\end{array}$ & 64.94 & 100.00 & & & Not Tree & 51.06 & 48.00 & \\
\hline & \multirow{2}{*}{20190417} & Tree & 97.44 & 77.55 & 87.88 & \multirow{2}{*}{20190406} & Tree & 66.04 & 70.00 & 6500 \\
\hline & & $\begin{array}{l}\text { Not } \\
\text { Tree }\end{array}$ & 81.67 & 98.00 & & & Not Tree & 66.67 & 60.00 & \\
\hline & & & & & & & & & & \\
\hline & \multirow[t]{2}{*}{20190703} & Tree & 84.85 & 56.00 & 73.00 & \multirow[t]{2}{*}{20170715} & Tree & 44.23 & 46.00 & 41.00 \\
\hline & & $\begin{array}{l}\text { Not } \\
\text { Tree }\end{array}$ & 67.16 & 90.00 & & & Not Tree & 40.00 & 36.00 & \\
\hline & & & & & & & & & & \\
\hline \multirow[t]{11}{*}{12} & \multirow[t]{2}{*}{20191116} & Tree & 96.08 & 98.00 & & \multirow[t]{2}{*}{20191122} & Tree & 92.45 & 98.00 & 95.00 \\
\hline & & $\begin{array}{l}\text { Not } \\
\text { Tree }\end{array}$ & 97.96 & 96.00 & 97.00 & & Not Tree & 97.87 & 92.00 & \\
\hline & & & & & & & & & & \\
\hline & \multirow{2}{*}{20190226} & Tree & 96.15 & 100.00 & 98.00 & \multirow[t]{2}{*}{20190126} & Tree & 85.71 & 96.00 & 90.00 \\
\hline & & $\begin{array}{l}\text { Not } \\
\text { Tree }\end{array}$ & 100.00 & 96.00 & & & Not Tree & 95.45 & 84.00 & \\
\hline & & & & & & & & & & \\
\hline & \multirow[t]{2}{*}{20190522} & Tree & 93.33 & 84.00 & 89.00 & \multirow[t]{2}{*}{20190615} & Tree & 84.91 & 90.00 & 87.00 \\
\hline & & $\begin{array}{l}\text { Not } \\
\text { Tree }\end{array}$ & 85.45 & 94.00 & & & Not Tree & 89.36 & 84.00 & \\
\hline & & & & & & & & & & \\
\hline & \multirow[t]{2}{*}{20190820} & Tree & 97.37 & 74.00 & 86.00 & \multirow[t]{2}{*}{20180730} & Tree & 72.41 & 42.00 & 63.00 \\
\hline & & $\begin{array}{l}\text { Not } \\
\text { Tree }\end{array}$ & 79.03 & 98.00 & & & Not Tree & 59.15 & 84.00 & \\
\hline
\end{tabular}


Table A2. The individual error matrix of Kappa analysis results. A Z-statistic greater than 1.96 indicates the classification is better than random.

\begin{tabular}{|c|c|c|c|c|c|c|c|c|}
\hline \multicolumn{5}{|c|}{ PlanetScope } & \multicolumn{4}{|l|}{ Sentinel-2 } \\
\hline Site ID & Date & Kappa & Variance & Z-statistic & Date & Kappa & Variance & Z-statistic \\
\hline \multirow[t]{4}{*}{01} & 20180925 & 0.860 & 0.003 & 16.874 & 20190926 & 0.880 & 0.002 & 18.627 \\
\hline & 20181018 & 0.700 & 0.005 & 9.849 & 20181230 & 0.880 & 0.002 & 18.538 \\
\hline & 20180621 & 0.440 & 0.009 & 4.696 & 20180213 & 0.600 & 0.006 & 7.500 \\
\hline & 20180831 & 0.600 & 0.006 & 7.500 & 20190404 & 0.499 & 0.008 & 5.695 \\
\hline \multirow[t]{4}{*}{02} & 20191030 & 0.560 & 0.007 & 6.715 & 20181024 & 0.842 & 0.003 & 16.039 \\
\hline & 20190130 & 0.840 & 0.003 & 15.555 & 20190122 & 0.860 & 0.003 & 16.970 \\
\hline & 20190512 & 0.760 & 0.004 & 11.698 & 20190512 & 0.900 & 0.002 & 20.677 \\
\hline & 20190823 & 0.160 & 0.010 & 1.599 & 20190909 & 0.420 & 0.010 & 4.202 \\
\hline \multirow[t]{4}{*}{03} & 20181214 & 0.660 & 0.006 & 8.858 & 20171009 & 0.600 & 0.006 & 7.500 \\
\hline & 20190315 & 0.780 & 0.004 & 12.466 & 20181203 & 0.880 & 0.002 & 18.627 \\
\hline & 20190414 & 0.780 & 0.004 & 12.568 & 20190313 & 0.880 & 0.000 & 6.223 \\
\hline & 20190726 & 0.700 & 0.005 & 9.830 & 20180701 & 0.720 & 0.005 & 10.481 \\
\hline \multirow[t]{4}{*}{04} & 20191116 & 0.880 & 0.002 & 18.538 & 20191118 & 0.880 & 0.002 & 18.627 \\
\hline & 20190126 & 0.900 & 0.002 & 20.651 & 20190412 & 0.800 & 0.004 & 13.429 \\
\hline & 20190418 & 0.760 & 0.004 & 11.762 & 20170507 & 0.900 & 0.002 & 20.677 \\
\hline & 20190914 & 0.800 & 0.004 & 13.387 & 20190909 & 0.940 & 0.001 & 27.557 \\
\hline \multirow[t]{4}{*}{05} & 20191111 & 0.840 & 0.003 & 15.514 & 20191123 & 0.920 & 0.002 & 23.490 \\
\hline & 20181224 & 0.740 & 0.005 & 11.024 & 20171218 & 0.780 & 0.004 & 12.568 \\
\hline & 20190422 & 0.760 & 0.004 & 11.711 & 20180522 & 0.720 & 0.005 & 10.481 \\
\hline & 20190826 & 0.840 & 0.003 & 15.612 & 20190820 & 0.900 & 0.002 & 20.677 \\
\hline \multirow[t]{4}{*}{06} & 20191116 & 0.020 & 0.022 & 0.134 & 20191118 & 0.760 & 0.004 & 11.732 \\
\hline & 20190130 & 0.500 & 0.008 & 5.611 & 20190201 & 0.800 & 0.004 & 13.484 \\
\hline & 20190506 & 0.020 & 0.027 & 0.121 & 20190517 & 0.580 & 0.007 & 7.109 \\
\hline & 20190804 & 0.240 & 0.016 & 1.912 & 20190805 & 0.460 & 0.009 & 4.896 \\
\hline \multirow[t]{4}{*}{07} & 20191022 & 0.840 & 0.003 & 15.481 & 20191102 & 0.640 & 0.006 & 8.382 \\
\hline & 20190304 & 0.560 & 0.007 & 6.677 & 20190220 & -0.481 & 0.006 & -6.164 \\
\hline & 20190408 & 0.660 & 0.006 & 8.811 & 20190630 & 0.717 & 0.004 & 11.382 \\
\hline & 20190810 & 0.720 & 0.005 & 10.401 & 20190913 & 0.780 & 0.004 & 12.466 \\
\hline \multirow[t]{2}{*}{08} & 20191015 & 0.780 & 0.004 & 12.568 & 20191109 & 0.780 & 0.000 & 5.515 \\
\hline & 20190203 & 0.940 & 0.001 & 27.595 & 20190423 & 0.656 & 0.006 & 8.657 \\
\hline
\end{tabular}




\begin{tabular}{|c|c|c|c|c|c|c|c|c|}
\hline \multicolumn{5}{|c|}{ PlanetScope } & \multicolumn{4}{|l|}{ Sentinel-2 } \\
\hline \multirow[t]{3}{*}{ Site ID } & Date & Kappa & Variance & Z-statistic & Date & Kappa & Variance & Z-statistic \\
\hline & 20190508 & 0.700 & 0.005 & 9.901 & 20180715 & 0.800 & 0.004 & 13.429 \\
\hline & 20190823 & 0.820 & 0.003 & 14.412 & & & & \\
\hline \multirow[t]{4}{*}{09} & 20191108 & 0.316 & 0.010 & 3.100 & 20191110 & 0.660 & 0.006 & 8.824 \\
\hline & 20190226 & 0.640 & 0.006 & 8.333 & 20190305 & 0.460 & 0.009 & 4.853 \\
\hline & 20190522 & 0.660 & 0.006 & 8.793 & 20190519 & 0.560 & 0.007 & 6.691 \\
\hline & 20190901 & 0.780 & 0.004 & 12.527 & 20190807 & 0.360 & 0.010 & 3.518 \\
\hline \multirow[t]{4}{*}{10} & 20191028 & 0.920 & 0.002 & 23.490 & 20190211 & 0.380 & 0.011 & 3.594 \\
\hline & 20190204 & 0.460 & 0.009 & 4.896 & 20190412 & 0.513 & 0.008 & 5.769 \\
\hline & 20190518 & 0.580 & 0.007 & 7.105 & 20190719 & 0.734 & 0.005 & 10.707 \\
\hline & 20190830 & 0.860 & 0.003 & 16.855 & 20190909 & 0.600 & 0.006 & 7.500 \\
\hline \multirow[t]{4}{*}{11} & 20190927 & 0.460 & 0.008 & 5.043 & 20181202 & -0.180 & 0.010 & -1.814 \\
\hline & 20190225 & 0.460 & 0.009 & 4.853 & 20190116 & 0.125 & 0.012 & 1.534 \\
\hline & 20190417 & 0.757 & 0.004 & 11.623 & 20190406 & 0.314 & 0.008 & 3.414 \\
\hline & 20190703 & 0.460 & 0.008 & 5.043 & 20170715 & -0.146 & 0.009 & -1.557 \\
\hline \multirow[t]{4}{*}{12} & 20191116 & 0.940 & 0.001 & 27.557 & 20191122 & 0.900 & 0.002 & 20.677 \\
\hline & 20190226 & 0.960 & 0.001 & 34.311 & 20190126 & 0.800 & 0.004 & 13.387 \\
\hline & 20190522 & 0.780 & 0.004 & 12.496 & 20190615 & 0.740 & 0.005 & 11.010 \\
\hline & 20190820 & 0.720 & 0.005 & 10.481 & 20180730 & 0.260 & 0.012 & 2.420 \\
\hline
\end{tabular}




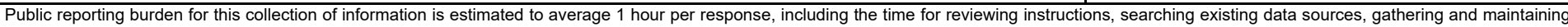

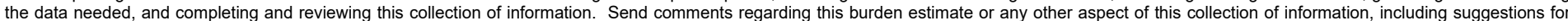

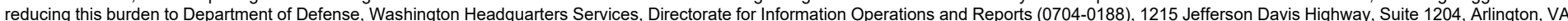

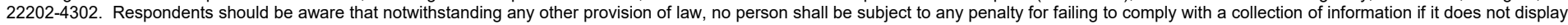
a currently valid OMB control number. PLEASE DO NOT RETURN YOUR FORM TO THE ABOVE ADDRESS.
1. REPORT DATE (DD-MM-YYYY) 2. REPORT TYPE
3. DATES COVERED (From - To)

September 2021

Final

\section{TITLE AND SUBTITLE}

A Multi-biome Study of Tree Cover Detection Using the Forest Cover Index

\section{5a. CONTRACT NUMBER}

5b. GRANT NUMBER

5c. PROGRAM ELEMENT NUMBER PE 633463

\section{AUTHOR(S)}

Sarah J. Becker, Megan C. Maloney, and Andrew W. H. Griffin

5d. PROJECT NUMBER

AU1

5e. TASK NUMBER

5f. WORK UNIT NUMBER

7. PERFORMING ORGANIZATION NAME(S) AND ADDRESS(ES)

8. PERFORMING ORGANIZATION REPORT NUMBER

Geospatial Research Laboratory

U.S. Army Engineer Research and Development Center

ERDC/GRL TR-21-4

7701 Telegraph Road

Alexandria, VA 22315

9. SPONSORING / MONITORING AGENCY NAME(S) AND ADDRESS(ES)

10. SPONSOR/MONITOR'S ACRONYM(S)

Engineer Research and Development Center

Alexandria, VA 22315

11. SPONSOR/MONITOR'S REPORT NUMBER(S)

\section{DISTRIBUTION / AVAILABILITY STATEMENT}

Approved for public release; distribution is unlimited.

\section{SUPPLEMENTARY NOTES}

\section{ABSTRACT}

Tree cover maps derived from satellite and aerial imagery directly support civil and military operations. However, distinguishing tree cover from other vegetative land covers is an analytical challenge. While the commonly used Normalized Difference Vegetation Index (NDVI) can identify vegetative cover, it does not consistently distinguish between tree and low-stature vegetation. The Forest Cover Index (FCI) algorithm was developed to take the multiplicative product of the red and near infrared bands and apply a threshold to separate tree cover from non-tree cover in multispectral imagery (MSI). Previous testing focused on one study site using 2-m resolution commercial MSI from WorldView-2 and 30-m resolution imagery from Landsat-7. New testing in this work used 3-m imagery from PlanetScope and 10-m imagery from Sentinel-2 in imagery in sites across 12 biomes in South and Central America and North Korea. Overall accuracy ranged between $23 \%$ and $97 \%$ for Sentinel-2 imagery and between $51 \%$ and $98 \%$ for PlanetScope imagery. Future research will focus on automating the identification of the threshold that separates tree from other land covers, exploring use of the output for machine learning applications, and incorporating ancillary data such as digital surface models and existing tree cover maps.

\begin{tabular}{|ll|}
\hline 15. SUBJECT TERMS & Tree cover \\
Forest Cover Index (FCI) & Forest cover \\
NDVI & PlanetScop \\
\hline
\end{tabular}

16. SECURITY CLASSIFICATION OF:

\section{a. REPORT}

Unclassified b. ABSTRACT

Unclassified

\section{c. THIS PAGE}

Unclassified

17. LIMITATION
OF ABSTRACT
SAR

Sentinel-2

Multispectral imagery

Vegetation index
18. NUMBER 19 a. NAME OF RESPONSIBLE OF PAGES

40

\section{PERSON}

19b. TELEPHONE NUMBER (include area code) 